Neurol Clin. 2014 August ; 32(3): 595-628. doi:10.1016/j.ncl.2014.04.007.

\title{
Idiopathic Inflammatory Myopathies
}

\author{
Mazen M. Dimachkie, MD, \\ Professor of Neurology, Director, Neurophysiology Division, Director, Neuromuscular Section, \\ Department of Neurology, University of Kansas Medical Center, 3901 Rainbow Blvd, Mail Stop \\ 2012, Kansas City, KS 66160, Phone: 913.588.6970, Fax: 913.588 .0609
}

Richard J. Barohn, MD, and

Gertrude and Dewey Ziegler Professor, Chairman, Department of Neurology, University Distinguished Professor, University of Kansas Medical Center, 3901 Rainbow Blvd, Mail Stop 2012, Kansas City, KS 66160

\section{Anthony Amato, MD}

Professor of Neurology, Harvard Medical School, Vice-Chairman, Department of Neurology, Brigham and Women's Hospital, 75 Francis Street, Boston, MA 02115

Mazen M. Dimachkie: mdimachkie@kumc.edu

\section{Abstract}

The idiopathic inflammatory myopathies (IIM) consist of rare heterogenous autoimmune disorders that present with marked proximal and symmetric muscle weakness, except for distal and asymmetric weakness in inclusion body myositis (IBM). Besides frequent creatine kinase (CK) elevation, the electromyogram confirms the presence of an irritative myopathy. Extramuscular involvement affects a significant number of cases with interstitial lung disease (ILD), cutaneous in dermatomyositis (DM), systemic or joint manifestations and increased risk of malignancy especially in DM. Myositis specific autoantibodies influence phenotype of the IIM. Jo-1 antibodies are frequently associated with ILD and the newly described HMG-CoA reductase antibodies are characteristic of autoimmune necrotizing myopathy (NM). Muscle pathology ranges from inflammatory exudates of variable distribution, to intact muscle fiber invasion, necrosis, phagocytosis and in the case of IBM rimmed vacuoles and protein deposits. Despite many similarities, the IIM are a quite heterogeneous from the histopathological and pathogenetic standpoints in addition to some clinical and treatment-response difference. The field has witnessed significant advances in our understanding of pathophysiology and treatment of these rare disorders. In this review, we focus on DM, polymyositis (PM) and NM and examine current and promising therapies. The reader interested in more details on IBM is referred to the corresponding chapter in this issue.

\footnotetext{
(c) 2014 Elsevier Inc. All rights reserved.
}

Correspondence to: Mazen M. Dimachkie, mdimachkie@kumc .edu.

Publisher's Disclaimer: This is a PDF file of an unedited manuscript that has been accepted for publication. As a service to our customers we are providing this early version of the manuscript. The manuscript will undergo copyediting, typesetting, and review of the resulting proof before it is published in its final citable form. Please note that during the production process errorsmaybe discovered which could affect the content, and all legal disclaimers that apply to the journal pertain. 


\section{Keywords}

Polymyositis; dermatomyositis; necrotizing myopathy; inclusion body myositis; clinical presentation; diagnosis; pathology; treatment; rehabilitation; research

\section{EPIDEMIOLOGY}

The IIM are rare sporadic disorders with an overall annual incidence of approximately one in 100,000. (Table 1) Except for juvenile dermatomyositis (JDM), the IIM are diseases of the adult and besides IBM these affect more women than men. In a Dutch study that excluded IBM, NM represented 19\%, while DM and non-specific myositis accounted for $36 \%$ and $39 \%$ of all IIM, respectively. ${ }^{1}$ Unlike findings from other studies, PM was reported to be uncommon, accounting for only $2 \%$ of IIM cases. ${ }^{1}$ However, a PM clinical phenotype was the most common cause of PM pathology in the Mayo Clinic case series. ${ }^{2}$ Indeed, 27/43 cases with PM pathology had clinical features of PM, while $37 \%$ had phenotypic IBM with tissue inflammation but no rimmed vacuoles. Studies of the combined incidence of PM and DM from Israel, South Australia and in the US (Allegheny County, PA and Olmestead county, $\mathrm{MN}$ ) have yielded rates ranging from 2.2 to 7.0 per million population using a variety of methods. ${ }^{3}$ The incidence of DM in South Australia is to 1.0 to 1.4 per million but in Olmstead County is 9.6 per million inhabitants. The incidence of PM in South Australia derived from muscle biopsy findings and review of medical records is four times higher than that of DM, respectively 4.1 to 6.6 per million versus 1.0 to 1.4 per million. A recent study indicates the prevalence rates in South Australia to be 1.97 and 7.2 per 100,000 for DM and PM respectively. In a nationwide Taiwanese population survey between 2003 and 2007, the overall annual incidences of DM and PM were 7.1 (95\% CI 6.6-7.6) and 4.4 (95\% CI 4.04.8) cases per million population. The incidence of DM and PM increased with advancing age and reached a peak at age $50-59$ years. ${ }^{4}$

\section{CLINICAL PRESENTATION DERMATOMYOSITIS}

The presentation of DM is cutaneous, muscular or both with acute to insidious progressive proximal muscle weakness. As in PM and NM, patients describe in DM difficulty using their arms while elevated above the head and being unable to get up from a deep chair, off the floor or to climb stairs. Formal grip force measures are reduced in chronic DM and PM as compared to controls. ${ }^{5}$ Weakness is painless except in patients with acute disease and/or subcutaneous calcifications. DM may result in bulbar muscle weakness manifesting as dysphagia, chewing difficulty, jaw opening weakness and sometimes dysarthria. In addition, multisystem involvement is common in juvenile DM which commonly presents as an insidious muscle weakness and pain after a febrile episode and skin rash.

The characteristic skin rash antedates or occurs concurrently with the onset of muscle weakness, thereby providing early clues to the diagnosis of classic DM. Adermatopathic DM is more difficult to recognize as it is histopathologically proven DM without the rash. Amyopathic DM presents with only the skin rash and no weakness though muscle histology may show some imflammation. Though classic DM rash can be quite sublte, a heliotrope 
rash is typical and consists of purplish discoloration of the eyelids often associated with periorbital edema (see Figure 1a). However, generalized or limb edema is an uncommon manifestation of DM. Gottron's papules (see Figure 1b), a violaceous lichenoid papular pathognomonic scaly rash, appear on the extensor surface of the hands fingers elbows and at times the toes. When occasionally located on the volar aspects, the papules are referred to as Inverse Gottron's Papules. ${ }^{6}$ A macular erythematous rash may affect the face, neck, and anterior chest ("V-sign"), upper back ("shawl sign"), the extensor surface of the elbows, knuckles (see Figure 1b), knees or toes (Gottron's sign). At times, the nail beds have dilated capillary loops with importantly periungal hyperemia (see Figure 1c). Nailfold capillary density is a reduced in JDM and is inversely associated over time with muscle and skin disease activity. ${ }^{7}$ Subcutaneous calcinosis of the elbows and knees with at times ulceration often occurs in juvenile DM but is uncommon in adult DM. "Mechanic's hands", manifesting as thickened and cracked skin on the dorsal and ventral surfaces of the hands, is encountered in patients with the antisynthetase syndrome (arthritis, Raynaud's phenomenon, interstitial lung disease). Cutaneous symptoms including prominent pruritus, have a significant impact on quality of life. ${ }^{8,9}$

Bohan and Peter described 5 criteria which when present support definite DM including proximal weakness, elevated CK, myopathic EMG, inflammatory pathology and typical rash which sets it apart from PM. ${ }^{10,11}$ Since then, a modification of the Bohan and Peter was reported by Targoff and colleagues who introduced a sixth criterion of myositis-specific autoantibodies as performed by a validated assay. ${ }^{12}$ This allowed patients fulfilling 4 out of 6 criteria to be diagnosed with definite DM or PM. A group of international experts met in Naarden and published proposed classification criteria of the IIM to improve diagnosis specificity. ${ }^{13}$ This system is based on clinical criteria, CK elevation, other laboratory criteria and better defined muscle biopsy criteria as detailed in Table 2. DM is classified as definite, probable, amyopathic and possible DM sine dermatatitis (Table 3). Definite DM requires pathologic evidence of perifascicular atrophy whereas probable DM is based on either perivascular perimysial inflammatory cell infiltrate, MAC depositions on small blood vessels, reduced capillary density, tubuloreticular inclusions in endothelial cells on EM, or MHC-1 expression on perifascicular fibers. These pathologic features in the absence of typical skin rash are sufficient for the diagnosis of possible DM sine dermatatitis. Muscle biopsy in amyopathic DM does not reveal features compatible with definite or probable DM.

\section{POLYMYOSITIS}

Since the Bohan and Peter criteria publication nearly four decades ago, ${ }^{11} \mathrm{PM}$ has been defined as an exclusionary diagnosis in patients who do not have a rash or alternate muscle or nerve disease. Though the existence of PM was recently brought into question, ${ }^{1,14}$ recent studies have confirmed it as a distinct clinical entity accounting for most (63\%) of patients with histologically-demonstrable findings of PM. ${ }^{2}$ Revised classification criteria (Tables 2 and 3) were recently advanced to factor in advances in our understanding of PM immunopathogenesis. ${ }^{13}$

PM affects adults over the age of 20 years and is more common in women than in men. ${ }^{11,15,16}$ Since there is no pathognomonic skin rash, diagnosis is often more delayed in 
PM as compared to DM. Patients develop progressive neck flexor and symmetric proximal limb muscle weakness subacutely or insidiously over weeks to months. Distal muscles are relatively spared. Though myalgias and muscle tenderness are common, these are not presenting complaints but rather weakness or dysphagia occurs in one-third of patients. In patient with acute quadriparetic presentation, weakness of jaw-opening was noted in $71 \%$ of PM/DM cases whereas this was rarely present (4\%) in the Guillain-Barré syndrome. ${ }^{17}$ Though mild facial weakness is occasionally present, extraocular muscles and sensation are spared. Tendon reflexes are normal except in severely weak muscles where they may be reduced.

\section{NECROTIZING MYOPATHY}

While NM may be due to toxic exposure, autoimmune NM is a unique progressive myopathy with distinct pathologic features, namely little or no inflammatory infiltrate besides intense myophagocytosis (Tables 2 and 3). ${ }^{13}$ As in PM, NM presents as a subacute to insidious progressive proximal muscle weakness without a rash but is more severe in tempo and in 30\% more marked in severity. ${ }^{1}$ There may be associated myalgia and in some cases dysphagia. In the Dutch case series, ${ }^{1}$ NM occurred in $19 \%$ of 165 IIM cases, and affected adults over the age of 30 with a female-to-male ratio of 2/1. In an Australian case series, the mean age of diagnosis was 57 years for NM and 61 years for the IIM with a wide range. ${ }^{18}$ Strangely, there were more males than females in that series but as expected median CK with NM (1,941 units per liter (U/L)) was significantly higher than in the other IIM.

Besides rheumatologic disorders, autoimmune NM may be associated with neoplasms, thick pipestems on muscle pathology, the signal recognition particle (SRP) autoantibody, statin therapy, or may be, by exclusion, idiopathic. Paraneoplastic NM is a rare, rapidly progressive, severe variant of NM that affects adults over the age of 40. NM with pipestem capillaries affects a similar age group and is associated with subacute weakness, brain infarction due to vasculitis, or connective tissue disease. Signal recognition particle (SRP) autoantibodies affect younger NM patients, women more than men, with typical onset in the fall season of severe fulminant weakness. While the original report suggested an increased risk for congestive heart failure, this has not been supported by other studies. Treatment refractory SRP-associated NM cases have been reported in childhood as young as age 5, with initial misdiagnosis including facioscapulohumeral muscular dystrophy (asymmetric shoulder girdle muscle involvement) and limb girdle muscular dystrophy. ${ }^{19}$

We have coined the term statin-associated autoimmune NM (SANAM) ${ }^{20}$ to refer to cases in whom statins induce an autoimmune NM which progresses beyond three to six months after drug discontinuation. ${ }^{21}$ While statins are ubiquitously used, $82 \%$ of NM patients had history of statin use, compared to $18 \%$ in DM, $24 \%$ in PM and $38 \%$ for IBM. ${ }^{21}$ SANAM affects individuals between 46 and 89 years of age (mean 65.5 years) with onset of SANAM being at times delayed by up to 10 years following statin initiation. While it commonly begins during statin use, onset in a third of cases may be 0.5-20 months after statin cessation for an elevated CK. The vast majority required immunosuppressive therapy, suggesting an autoimmune mechanism. Otherwise, NM may be idiopathic in the remainder of cases. Anti- 
HMGCoAR antibodies have recently been described in SANAM and idiopathic NM (see below).

\section{CONDITIONS ASSOCIATED WITH DM, PM \& NM}

There is an increased incidence of ILD, autoimmune disorders, cancer and possibly cardiac involvement in the IIMs. In juvenile DM, necrotizing vasculitis may complicate the gastrointestinal system with bowel ischemia, necrosis, and perforation with associated petechial rash or even muscle infarcts. In the IIM, inflammation of gastrointestinal tract smooth muscles results in dysphagia, aspiration pneumonia, and delayed gastric emptying. In JDM cases, there is a strong family history of other autoimmune disease, particularly type 1 diabetes and systemic lupus erythematosus. ${ }^{22}$

Polyarthritis has been reported in nearly half of patients with PM at the time of diagnosis. ${ }^{23}$ Scleroderma and mixed connective tissue disease are frequently associated with NM. Ten to twenty-five percent of adult IIM patients have ILD which manifests as dyspnea and cough. ${ }^{24}$ In most instances the diagnosis of ILD is made concurrently with that of the muscle disease but in a third of ILD cases, it may antecede or follow the diagnosis of PM or DM. Including the $5 \%$ asymptomatic myositis subjects despite evidence of ILD on pulmonary function testing and chest imaging, ILD may affect up to $30 \%$ of DM and PM cases. ${ }^{24} \mathrm{~A}$ chronic progressive course is most common while $5 \%$ may have an acute presentation. ILD may occur in juvenile DM and has been reported in upward of $10 \%$ of PM cases, with the majority having Jo-1 antibodies ${ }^{25,12}$ which are more associated with DM than with PM. ${ }^{1}$

While rates of malignancy have been reported to be as high as $45 \%,{ }^{26}$ most studies suggest that $15 \%{ }^{27}$ to $25 \%{ }^{28}$ of adult DM cases, and especially in those who are older than 40 years, have preexisting, concurrent or future malignancies. In women, the most common DMassociated malignancy is ovarian cancer, ${ }^{29}$ and in men it is small cell lung cancer whereas nasopharyngeal carcinoma in common in Southeast Asia, Southern China, and Northern Africa. Treatment of the malignancy, which may present two years after the DM onset, improves muscular involvement. Rarely, malignancies including hematologic disorders have been reported in juvenile DM. ${ }^{30}$ The risk of malignancy is modestly increased in PM and NM when compared to the general population. ${ }^{31}$ In Taiwan, $13.8 \%$ of DM patients and 6.2\% of PM patients had cancers. Overall standardized incidence ratios for cancer were 5.36 for DM cases and 1.80 among PM patients but were even higher in the first year at 24.55 and 9.17 respectively. ${ }^{4}$ Gastrointestinal tract adenocarcinoma and small and non-small cell carcinoma of the lung are common malignancies in paraneoplastic autoimmune NM.

Statins can trigger SANAM, an autoimmune NM, which is rare and is distinct from the more common toxic NM with statin use. ${ }^{22,32}$ Other drugs associated with toxic NM include fibrates, ezetimibe, cyclosporine, labetolol, propofol and alcohol. In the Dutch case series, ${ }^{1}$ ten percent of NM cases were associated with collagen vascular disease and in an Australian case series, systemic lupus erythematosus occurred in $21 \% .{ }^{18}$ Finally, there are patients with NM who have no known associated conditions or precipitating factors, and these are considered to have an idiopathic immune-mediated myopathy. ${ }^{33}$ 
While cardiac conduction defects and arrhythmias may occur in the IIMs, pericarditis and congestive heart failure have been less commonly described. Up to 1/3 of PM cases may have myocarditis which manifests primarily as conduction abnormalities and much less commonly as congestive heart failure. SRP autoantibodies predict a fulminant form of refractory PM or NM that rapidly progresses over one month to severe weakness and though this point has become controversial, may be associated with myocarditis. ${ }^{34}$ There is an overall increase in cardiovascular disease risk with the IIM. ${ }^{35,36}$

\section{LABORATORY STUDIES IN DM, PM \& NM}

Serum CK level is increased up to 50 times the upper normal limit in the majority of DM patients. However, $10 \%$ of DM cases regardless of severity have normal CK level especially in adults with insidious disease and in JDM. In contrast, CK is always elevated in active PM in the range of five to 50 times the upper normal limit and is at least 10 times increased in NM. While the degree of CK abnormality does not correlate well with the severity of weakness, a decrease or increase in CK level generally correlates with good treatment response or relapse respectively and is a useful measure of disease activity in conjunction with manual muscle testing. It is rare for serum aldolase to be elevated without a $\mathrm{CK}$ abnormality. The erythrocyte sedimentation rate may be elevated but does not correlate with disease activity. An isolated positive ANA, as occurs in some IIM patients, is of unclear significance.

Screening for malignancy is important in DM but also NM and PM, especially in the first few years following diagnosis. In a study of 618 Caucasian patients with DM, Hill et al. found that DM was strongly associated with various types of malignancies (OR: 3 ), including especially ovarian (OR: 10.5), lung (OR: 5.9), but also pancreatic, stomach and colo-rectal cancers. ${ }^{37}$ In 914 Caucasian patients with PM, these investigators also reported that PM was associated with lung (OR: 2.8) and bladder cancers (OR: 2.4). More recently, an increased risk of hematologic malignancies, mostly B-cell lymphoma, has been reported in older DM patients. ${ }^{38}$ Data on cost-effectiveness of cancer screening in DM is limited to retrospective case series. Some have suggested that further testing, beyond a thorough evaluation by an internist, a chest X-ray and in women pelvic examination and mammogram, be guided by abnormal symptoms or results. Others, however, found that routine CAT scans of the chest and abdomen and in women pelvic CAT scan optimize cancer detection. ${ }^{39}$ Our approach includes a careful skin examination for melanoma, CAT scan of the chest, abdomen and pelvis, and in women, a mammogram and pelvic examination; whereas in men, testicular and prostate examinations are indicated. We advocate in women a pelvic sonogram to better evaluate them for the most common associated malignancy, ovarian cancer. In those over the age of 50, we recommend a colonoscopy rather than a stool occult blood. More recently, the EFNS task force recommended that in DM, patients should have CT of the chest/abdomen, pelvic ultrasound and mammography in women, US of testes in men under 50 years and colonoscopy in men and women over 50. If primary screening is negative, repeat screening is recommended after 3-6 months and thereafter screening is every 6 months up till 4 years. ${ }^{40}$ We believe that repeat screening decisions are best guided by the clinical context. 
Symptoms of ILD should prompt pulmonary consultation including chest imaging and pulmonary function testing. Chest X-ray is less sensitive than a CT scan but reveals diffuse reticulonodular infiltrates and in more severe ILD cases a ground-glass appearance. Highresolution chest CT scan has a higher sensitivity in detecting milder ILD changes. Pulmonary function testing reveals abnormal forced vital capacity and lung diffusion. The course of ILD is quite variable, and may be static and asymptomatic (30\%), slowly progressive (50\%) or fulminant (20\%). ${ }^{41}$ Jo-1 (histidyl t-RNA synthetase) antibody occurrs in $50 \%$ of myositidis afflicted with ILD 25,12 and progressive ILD cases have a high mortality. Of the antisynthetase antibodies, anti-PL-7 and anti-PL-12 antisynthetase antibodies are strongly associated with ILD in $90-100 \%$ of cases and gastrointestinal complications. ${ }^{42,43}$ Presence of anti-PL12 antibody is associated with less frequent although severe/steroid refractory myositis and ILD that is both frequent and severe. ${ }^{44}$ In clinically amyopathic DM, anti-CADM-140 (MDA5/IFIH1) antibodies were thought originally to be markers of acute rapidly progressive ILD with very poor prognosis. ${ }^{45}$ In another case series however, MDA-5 autoantibodies were found in DM patients presenting with the antisynthetase syndrome, but in the absence of antisynthetase autoantibodies. ${ }^{46}$ Most antiMDA-5-positive patients had ILD which was occasionally severe yet typically resolved with immunosuppressive therapy.

The $\mathrm{G}$ allele of interferon-induced helicase (IFIH1) was found to be protective against ILD while the AA genotype was identified as a risk factor for lung injury in PM. ${ }^{47}$ The combination of anti-Jo- 1 and anti-SSA/Ro antibodies is a marker of severe ILD. ${ }^{42}$ Besides serial imaging and pulmonary function testing, serum KL-6, ${ }^{48}$ SP-D, IL-18 and ferritin levels may be useful biomarkers for monitoring ILD activity and severity. ${ }^{49}$ The lower consolidation / ground-glass attenuation pattern, and the presence of anti-CADM-140 were significantly associated with 90 -day mortality. ${ }^{50}$ There is a positive correlation of B cellactivating factor (BAFF) and $\triangle \mathrm{BAFF}$ expression with $\mathrm{PM} / \mathrm{DM}$ disease activity measures assessed by the International Myositis Assessment and Clinical Studies core set tool. ${ }^{51} \mathrm{Up}$ regulation of resistin in muscle tissue and elevated serum resistin levels in the IIMs reflected global disease activity, including extramuscular organ involvement. However, there are currently no sufficient data to distinguish the features of resistin that cause injury of muscle tissue from those that promote muscle regeneration and repair. ${ }^{52}$

Though there are no published prospective studies, current experience suggests that most of the so-called myositis-specific antibodies (MSAs) predict poor treatment response due to the association with ILD. However, these antibodies, which are only present in a minority of DM patients, have an unknown and controversial pathogenetic role in the IIMs. The MSAs include two classes of cytoplasmic antibodies: those directed against Mi-2 and Mas antigens and others targeting translational proteins such as various tRNA synthetases, the SRP, transcriptional intermediary factor-1 (TIF1;anti-155/140 Ab) and the melanoma differentiation-associated gene-5 (MDA5; anti-CADM140 Ab) ${ }^{53}$ While most patients have no detectable MSAs and a rare case may have two detectable MSAs, $, 54,55$ those that have it carry mostly one MSA type in association with specific HLA haplotypes., ${ }^{1,56}$

The Jo-1 antibody is associated with ILD, arthritis, Raynaud's phenomenon, and mechanic's hand's, ${ }^{12}$ and is seen in up to $20 \%$ of IIMs. ${ }^{25,}{ }^{12}$ The frequent association of Jo-1 antibodies 
with ILD may be the basis for moderate treatment response and poor long-term prognosis. ${ }^{57}$ The other antisynthetases (PL-7, PL-12, EJ, KS, OJ) are less common, occurring in fewer than $2 \%$ to $3 \%$ of IIM cases. Anti-OJ ILD positive patients with PM/DM lack the manifestations of Raynaud's phenomenon and sclerodactyly and show good prognoses and responses to glucocorticoid therapy. ${ }^{58}$ Antibodies to nuclear matrix protein NXP2, previously known as MJ antibodies, are amongst the most common MSAs in JDM but occur in less than $2 \%$ of adult DM cases with up to $50 \%$ having an associated adult malignancy. ${ }^{53}$

Nonsynthetase antibodies to Mi-2 are found in $15 \%$ to $30 \%$ of DM patients and are associated with acute onset, an erythematous rash, nail bed capillary dilation, good response to therapy, and favorable prognosis. ${ }^{12,57}$ However, it is unknown whether DM cases with Mi-2 antibody respond differently from those without this antibody.

While anti-Mi-2 is associated with classical DM without ILD or malignancy, anti-155/140 is associated with malignancy in adults and patients with anti-CADM-140 frequently had clinically amyopathic DM and rapidly progressive interstitial lung disease. Upward of 70\% of Japanese adult DM cases harboring anti-TIF1 have a malignancy. ${ }^{59}$ However, antip155/140 autoantibody subgroup in juvenile myositis included Gottron papules, malar rash, "shawl-sign" rash, photosensitivity, cuticular overgrowth, low CK levels, and a predominantly chronic illness course without malignancy.$^{60}$ In a DM case series, 20/55 had ILD but rapidly progressive ILD was present in 3 cases all of whom had anti-CADM-140 antibodies whereas those with anti-tRNA synthetase antibodies had slow progression of ILD. ${ }^{61}$ Nearly half of DM-ILD cases have serological evidence of these autoantibodies. ${ }^{62}$ Though most patients with clinically amyopathic DM do not harbor anti-CADM-140, the prevalence of muscle involvement in patients with anti-CADM-140 may be up to $83 \% .{ }^{61} \mathrm{In}$ a JDM series, CADM-140 antibody was positive in 5/6 patients with ILD but was absent in all 7 cases without ILD. ${ }^{63}$

SRP antibodies have been reported in up to 5-8\% of "PM" cases and are mostly associated with the phenotype of NM. ${ }^{64}$ Patients present in the fall with rapidly progressive proximal severe weakness that often responds poorly to steroid therapy. ${ }^{65}$ There is associated ILD and possibly cardiac involvement. Rarely, PM patients may be positive for both the SRP antibody and a non-Jo- 1 antisynthetase antibody, ${ }^{1}$ and an MSA may be present in up to $1 / 3$ of NM cases. In a case series, one NM patient harbored antibodies to both Mi- 2 and a nonJo-1 antisynthetase. ${ }^{1}$ SRP antibodies may be non-specifically positive in patients with alternate muscle diagnosis or no evidence of muscle involvement. ${ }^{66}$

We routinely obtain Jo- 1 antibodies on all IIM cases. Since $50 \%$ of Jo-1 positive cases either already have or will develop ILD, we avoid using methotrexate in those patients. Antibodies to SRP are especially indicated in severe fulminant PM or NM since they predict a rapid course leading to muscle fibrosis and marked cardiac involvement, dictate the need for aggressive and swift pharmacotherapy and may portend a poor prognosis.

Anti-200/100 autoantibodies characterized a unique subset of patients with myopathies, representing $62 \%$ of patients with idiopathic necrotizing myopathies. ${ }^{67}$ Of those 16 
antibody-positive cases, 10 were previously exposed to statins. The target antigen has been identified and it is the HMG-CoA reductase.

\section{ELECROPHYSIOLOGY OF DM, PM \& NM}

Nerve conduction studies are normal except for compound muscle action potential (CMAP) amplitude reduction in fulminant cases associated with severe diffuse muscle weakness. This finding should prompt the electromyographer to evaluate for the Lambert-Eaton Myasthenic syndrome. Needle electromyography (EMG) shows at rest increased insertional, small-amplitude low-frequency fibrillation potentials, and occasionally scattered pseudomyotonic or complex repetitive discharges indicating chronicity. Besides proximal myotonic myopathy, diffuse electrical myotonia is a prominent finding in SANAM. On activation, the proficient electromyographer readily identifies polyphasic motor unit action potentials (MUAPs) of low amplitude and more importantly of reduced duration especially in the proximal musculature. The crisp sound of these MUAPs is distinctive in addition to direct visualization and measurement of MUAP duration. Activation of MUAPs shows an early recruitment pattern due to central compensation except in severe cases where recruitment might be reduced. With chronicity, reinnervation of split fibers produces MUAPs of increased duration.

In addition to its diagnostic utility and ability to target muscle biopsy, EMG is helpful in assessing relapsing weakness during treatment with corticosteroids. In previously responsive myositis, worsening strength in the absence of fibrillation potentials on NEE suggests steroid-induced myopathy/type 2 muscle fiber atrophy which is a rare entity. Fibrillation potentials would confirm active myositis and the need for more immunosuppression.

\section{MUSCLE IMAGING}

In the absence of typical NEE findings, newer diagnostic criteria may allow the use of muscle MRI signal abnormality or presence of MSA to support of probable PM or DM (Table 2). ${ }^{13}$ Fat-suppressed and short tau inversion recovery skeletal muscle MRI may show fibrosis or diffuse or patchy signal symmetric increase in the proximal muscles and intermuscular fascia indicative of muscle edema due to inflammation. There is a relative sparing of the adductor, obturator, and pectineus muscles. ${ }^{68}$ Fat deposition on T1-weighted images usually appears after 3 to 5 months of disease duration and preferentially involves the hamstrings. While others may use muscle MRI, it is our experience that a proficiently performed EMG and clinical evaluation are sufficient for the selection of the optimal muscle to biopsy.

\section{MUSCLE HISTOPATHOLOGY AND PATHOGENESIS OF DM, PM \& NM DERMATOMYOSITIS}

Except for amyopathic cases, muscle biopsy is critical for the diagnosis of DM. The earliest detectable histological abnormality on light microscopy in DM is deposition of the C5b-9 or membrane attack complex of complement around small blood vessels. ${ }^{69}, 70$ This humorallymediated microangiopathy leads to decreased capillary density, especially at the periphery of the fascicle. It is fairly characteristic of DM and may explain the occasional infarction of 
muscle fibers in juvenile DM. Membrane attack complex deposition is highly sensitive and specific in differentiating DM from other IIMs. Capillary damage and myofiber atrophy are concentrated in regions distant from the affected intermediate-sized perimysial vessels leading to the suggestion that watershed ischemia is the cause of myofiber atrophy and capillary damage in regions of muscle near the avascular perimysium. ${ }^{71}$ The interferon- $\alpha-\beta$ inducible protein, myxovirus resistance (MxA), was recently found to be expressed in $90 \%$ of capillaries. ${ }^{72}$

Nearly half of muscle biopsies demonstrate perifascicular atrophy (Figure 2a), often without an inflammatory infiltrate. When present, the inflammatory infiltrate consists of predominantly perimysial and perivascular macrophages and B cells presenting a putative antigen to naïve CD4+ cells some of which are T-lymphocytes but most are plasmacytoid dendritic cells ( $\mathrm{pDC}$ ) (see Figure 2b). Invasion of non-necrotic fibers is not common. The incidence of rare-infiltrative lesions in those with malignant tumors (45\%) was significantly higher than in those without such tumors (14\%). The end result of this humoral microangiopathy is myofibril necrosis in groups and regeneration. The presentation is HLA class II restricted and leads to the maturation of CD4+ T cells and $\mathrm{pDC}$, depending on the cytokine environment, into Th1, Th2, Th17 or regulatory T cells (Treg). Th1 and Th17 activation produce proinflammatory cytokines present in myositis tissues and are associated with the migration, differentiation, and maturation of inflammatory cells, including dendritic cells (DC). Natural Tregs are CD4+CD25+ FoxP3+ whereas adaptive Tregs are induced in the peripheral immune system after encountering foreign antigens and have 2 distinct cytokine profiles. Treg type 1 secrete high levels of IL10, whereas T helper type 3 (Th3) cells secrete high levels of the profibrotic agent transforming growth factor (TGF) $-\beta .{ }^{74}$ Antiga et al found that the number of Treg cells in the peripheral blood of patients with DM was significantly reduced compared to healthy controls with a reduction in TGF- $\beta$ and IL-10 serum levels suggesting that Treg depletion may be an important factor in the pathogenesis of the disease. ${ }^{75}$ FOXP3 + Tregs are found in close proximity to effector cells and serve to counterbalance muscle destruction by cytotoxic T cells in myositis. ${ }^{76}$ Fascin-positive DC predominance in inflammatory infiltrates in in both PM and DM muscles confirms the prevalence of mature forms and indicates that there is stimulation of DC maturation. ${ }^{77}$

On electron microscopy, the earliest recognized changes are tubuloreticular inclusions in the intramuscular arterioles and capillaries. ${ }^{78} \mathrm{MxA}$ co-localizes to the small intramuscular blood vessel inclusions and is thought to form tubuloreticular inclusions around RNA viruses. ${ }^{72}$ Therefore the endothelial cell tubuloreticular inclusions present in affected dermatomyositis muscle are thought to be biomarkers of type 1 interferon exposure (see below).

Recent evidence from DM muscle-derived microarrays studies had uncovered an increase in MHC I and immunoglobulin gene transcripts ${ }^{79}$ and a robust increase in the expression of type 1 interferon-inducible genes up to 570 fold in addition to an abundant immunoglobulin gene transcript. ${ }^{72}$ The expression of MxA is localized to $50 \%$ perifascicular muscle fibers in addition to diffuse perifascicular major histocompatibility complex I (MHC I) positivity. MxA as the name indicates is inducible by type 1 interferons (IFN1). Type I IFNs are known to up-regulate MHC expression, activate natural killer cell cytotoxicity, promote activated T cell survival, and support DC maturation. Analysis of peripheral blood mononuclear cells 
demonstrates a high interferon- $\alpha / \beta$ signature which parallels disease activity in DM. ${ }^{80}$ IL-6, a proinflammatory cytokine, plays central roles in the regulation of both innate and adaptive inflammatory and immune responses, as well as both humoral and cell-mediated autoimmune reactions. Prominent type I IFN signatures, manifesting as both transcript upregulation and elevated levels of serum proteins, and elevated IL-6 levels in the patients' serum correlated strongly with DM disease activity. ${ }^{81}$ Comparing IFNa, IFN $\beta$ and IFN $\omega$ in DM, PM and IBM blood samples to healthy volunteers, IFN $\beta$ signature was uniquely associated with DM. It was detectable in $64 \%$ of samples from patients with untreated or minimally treated DM and $35 \%$ of all DM samples compared to $6 \%$ of other inflammatory myopathy and $6 \%$ of healthy volunteer samples. ${ }^{83}$

Additionally, evidence has emerged suggesting that not all CD4+ cells are T cells, and that 30 to $90 \%$ of these cells are CD4+/CD3- or plasmacytoid dendritic cells (pDC). ${ }^{72}$ The pDC are part of the innate immune system response to viral antigens and respond by producing a large amount of IFN1 once their Toll-like receptors (TLR-7 and TLR-9) binds to viral nucleic acids. TLR activation leads to the generation of cytokines and chemokines and to the maturation of antigen-presenting cells (APCs) by up-regulating costimulatory molecules that promote efficient interactions between APCs and T cells. This IFN signature was also noted in the active phase of other autoimmune disorders. IFN signature is seen in DM skin, similar to that found in the blood and muscle of DM patients. ${ }^{83}$

\section{POLYMYOSITIS}

Muscle biopsy is critical for the confirmation of PM and exclusion of mimics such as IBM but also muscular dystrophy, acid maltase deficiency and NM (Table 4). The histological features of PM are distinct from those seen in DM since PM is the result of an HLArestricted cell-mediated cytotoxic immune response directed at muscle fibers. Prominent microscopic features are fiber size variability, scattered necrotic and regenerating fibers, and endomysial inflammation. This consists primarily of activated CD8+ cytotoxic T cells, and macrophages that in $63 \%$ of cases invade non-necrotic muscle fibers ${ }^{2}$ expressing MHC-1 antigens (Figure 2c). This histological pattern is not distinctive as it also occurred in IBM patients too. ${ }^{2}$ MHC-1 antigens, which are not constituvely expressed, decorate the surface of non-invaded intact myocytes. Surface expression of MHC-1 is not specific to the IIM and can be seen in fascioscapulohumeral muscular dystrophy, Duchenne and Becker muscular dystrophy, statin-associated myopathy, dysferlinopathy and rarely other limb girdle muscular dystrophies and in merosin deficiency. A sarcoplasmic reticular pattern of internal MHC-1 reactivity was recently reported to be $70 \%$ sensitive and $100 \%$ specific to the IIM when using a cut-off value of $50 \% .^{76}$ It is thought that MHC-1 antigens express an unknown endogenous peptide which acts as the auto-antigen. The endomysial CD8+ cytotoxic T cells are antigen-specific and destroy myocytes through the perforin pathway. These are accompanied by abundant myeloid dendritic cells that surround non-necrotic fibers and act as antigen presenting cells. ${ }^{85} \mathrm{We}$ demonstrated increased immunoglobulin genes expression on muscle microarray experiments in PM. ${ }^{79,86}$ The immunoglobulins are secreted by endomysial plasma cells but, unlike DM, are not deposited in the muscle blood vessels. ${ }^{86}$ Type 1 IFN signature is significantly overexpressed in the blood of both DM and PM 
patients ${ }^{87}$ and significantly correlated with disease activity as measured by the modified Myositis Intention to Treat scale.

\section{NECROTIZING MYOPATHY}

Muscle histopathology is central to the diagnosis of NM. The hallmark of all autoimmune $\mathrm{NM}$ is the presence of scattered necrotic myofibers with myophagocytosis and either absence or paucity of T-lymphocytic inflammatory exudates (Figure 2d). In addition, microvascular deposition of complement membrane attack complex suggests a humorallymediated microangiopathy. Unlike DM, perivascular inflammation is scant, and there are no endothelial tubuloreticular inclusions on EM.

In addition to the above common pathologic features, a variety of distinctive findings occur in specific subtypes of NM. Demonstration of thick-walled and enlarged "pipestem" capillaries of normal number is diagnostic of NM with pipestem capillaries. ${ }^{88}$ Muscle connective tissue positively staining for alkaline phosphatase has been described in malignancy-associated NM. The SRP-associated NM demonstrates early in the course a bimodal distribution of fiber sizes in addition to increased endomysial connective tissue and reduced number together with enlargement and thickening of endomysial capillaries. Marked fibrosis is noted 6 months after its onset. The deposition of membrane attack complex on endomysial capillaries has been shown in biopsy specimens obtained from positive SRP positive patients. Upregulation of MHC class I antigens was present in a 9\% of idiopathic NM cases ${ }^{18}$ while in another case series, $75 \%$ of NM cases demonstrated that in $10 \%$ or more of the non-necrotic fibers. ${ }^{89}$

Muscle fibers of SANAM express on their surfaces MHC class I antigens in all 8 biopsy specimens, supporting the notion of an immune-mediated NM induced by endoplasmic reticulum stress. ${ }^{32}$ It is thought that the later leads to exposure of neoantigens thereby activating the immune system despite statin cessation. Though the pathophysiology of SANAM is uncertain, it is likely humorally-mediated NM mediated via cytokine expression and complement activation. ${ }^{22}$ The pathophysiology of NM has witnessed marked advances with the discovery of the anti-200/100 autoantibodies which target HMG-CoA reductase. ${ }^{67}$ These autoantibodies were identified 17 IIM cases; 16 had NM pathology and one had extensive inflammatory infiltrates. Out of a total $38 \mathrm{NM}$ cases, 12 had SRP antibodies and 16/26 remaining NM cases had the newly described 200/100 autoantibodies. Of these 16 NM cases, 10 were exposed to statins and 6 were not. Although close examination revealed endomysial and/or perivascular collections of inflammatory cells in 5 of the 16 muscle biopsy specimens, the degree of inflammation was mild compared with that seen in typical muscle biopsy specimens obtained from patients with PM or DM. Examination of frozen muscle tissue samples available in 8/16 patients revealed abnormally enlarged endomysial capillaries with thickened walls in 5 specimens with capillary density preservation. Although endomysial capillaries were not recognized by the membrane attack complex, small perimysial vessels stained positive in 6 of 8 muscle biopsy specimens. Unlike the findings of Needham et al, ${ }^{32}$ only 4 of 8 specimens demonstrated sarcolemmal MHC class I positivitity. Mamen et al subsequently identified the 100-kd antigen to be the 3-hydroxy-3methylglutarylcoenzyme A reductase (HMGCR) protein. ${ }^{90}$ In muscle biopsy tissues from 
antibody positive patients, HMGCR expression was up-regulated in cells expressing neural cell adhesion molecule, a marker of muscle regeneration. After statin cessation, high levels of HMGCR expression in regenerating muscle tissue might continue to drive the autoimmune response. Although other have reported genetic variants and mutations in the SLCO1B1, CYP and COQ2 genes as determinants to individual statin myopathy susceptibility, the prevalence of the rs4149056 C allele was not increased in patients with anti-HMGCR. In summary, the HMGCR autoantibody is present in $63 \%$ of NM cases with high specificity approaching $100 \%$. However, a puzzling finding is that $33 \%$ of antibody positive NM cases are statin-naive.

\section{THERAPY FOR DM, PM \& NM}

Immunosuppressive therapy is the mainstay of treatment in patients with active disease related to DM, PM and NM (Table 5). ${ }^{91}$ Autoimmune NM is often more resistant to immunosuppressive therapy than DM and PM, particularly if there is an underlying malignancy or a statin trigger. The overwhelming majority (23/25) of SANAM cases required more than one immunosuppressive agent with relapse in 12 cases following immunosuppressive therapy tapering. ${ }^{22}$ However as in DM and PM, immunosuppressants such as prednisone in combination with methotrexate (MTX) or azathioprine (AZA) are the first-line therapies in autoimmune NM. For resistant or severe cases, adding intravenous immunoglobulin (IVIG) may be helpful. Third line drugs include mycophenolate mofetil, cyclosporine, tacrolimus, rituximab, etanercept and cyclophosphamide.

The few published randomized controlled trials of immunosuppression in DM or PM compared placebo to azathioprine, ${ }^{92}$ plasma exchange ${ }^{93}$ or IVIG. ${ }^{94}$ In addition, randomized controlled trials compared methotrexate with azathioprine, ${ }^{95}$ cyclosporine with methotrexate, ${ }^{96}$ and intravenous methotrexate with oral methotrexate plus azathioprine. ${ }^{97}$ The only positive controlled trials are a small cross-over study of IVIG in $\mathrm{DM}^{94}$ and a randomized, double-blind, placebo-controlled trial of etanercept (50mg subcutaneously weekly) for 52 weeks in 16 DM subjects. ${ }^{98}$

\section{CORTICOSTEROIDS}

While no controlled trial has been done using corticosteroids (CS), there is general agreement that these are effective in DM, PM, and NM. CS can be used in a wide range of regimens and routes of administration. We administer prednisone $1 \mathrm{mg} / \mathrm{kg} / \mathrm{d}(60-100 \mathrm{mg})$ for four weeks followed by an abrupt or tapered conversion to an every other day (QOD) schedule. This taper is slower in patients with severe disease. A daily CS schedule is necessary in well-controlled hypertensive or non-brittle diabetic patients. While most patients feel immediately better after taking CS, strength improvement is delayed by two to three months after the onset of treatment. An immediate response may suggest an alternate diagnosis such as polymyalgia rheumatica (Table 4). For the first three months, the typical adult patient remains on prednisone 60 to $100 \mathrm{mg}$ every other day or its equivalent. If no improvement is noted after three to six months, or if weakness reoccurs during the taper, we start a second line immunosuppressive agent such as azathioprine, methotrexate or IVIG. We do initiate those early on with CS therapy in high risk patients such as in uncontrolled hypertension, diabetes, osteoporosis, obesity and in those with baseline severe weakness. 
For good responders, a taper by $20 \mathrm{mg}$ per month until $40 \mathrm{mg}$ QOD then by $10 \mathrm{mg}$ per month will reduce the prednisone dose to $20 \mathrm{mg}$ QOD after six to eight months from the initiation of therapy. After that, the taper is by $5 \mathrm{mg}$ and the interval is every three months to reach the minimal effective dose. In severe cases, we prefer starting with a five-day intravenous pulse methyprednisolone therapy followed by high dose oral prednisone in combination with a second line drug. Recently, a randomized multicenter double-blind clinical trial compared oral dexamethasone pulse therapy to daily prednisolone in 62 patients with subacute onset myositis. ${ }^{99}$ The pulsed regimen consisted of six cycles of dexamethasone given monthly as $40 \mathrm{mg} /$ day for four consecutive days. The main issue is that there was a large number of early disconstinuations in both groups for a variety of reasons. While pulsed high-dose oral dexamethasone was not found to be superior to daily prednisolone as first-line treatment of IIM, it also caused substantially fewer side-effects. Ten patients (33\%) treated with prednisolone and one patient (4\%) treated with pulsed dexamethasone developed diabetes mellitus. Mood changes occurred in 20 patients (67\%) and $8(29 \%)$, respectively. Treatment adjustments for co-morbid conditions (hypertension, diabetes mellitus) were needed in one patient in the dexamethasone group, compared with 15 patients in the prednisolone group.

Because the risks of long-term CS therapy are numerous, discussing those with the patient as well as establishing a monitoring plan in collaboration with the primary care physician is integral to the management plan. Before CS initiation, we place a PPD skin test or obtain a QuantiFERON®-TB Gold test to identify the need for isoniazid in previously exposed cases. As we start CS, we obtain a baseline bone DEXA scan and request the patient to seek an opthtalmologic examination, with yearly follow-up for both. We maintain patients on oral calcium 500 to $600 \mathrm{mg}$ two to three times daily with vitamin D 400 IU daily. In JDM, the incidence of vertebral fracture 12 months following steroid initiation was $6 \%$ and these were mostly asymptomatic. ${ }^{100}$ The risk of fracture increased with higher steroid dose, and in the first 6 months with greater increases in BMI or greater declines in spine $\mathrm{Z}$ scores. We ask patients and their families to be alert about personality changes and psychiatric side effects. We instruct patients to reduce salt and carbohydrates in their diet and visit regularly with the primary care physician for blood pressure, serum glucose and potassium and measurements. We advocate the pneumococcal vaccine and yearly flu shots. Given the immunosuppressed state, evidence suggested that seroprotection of the influenza $A / H 1 N 1$ vaccine is significantly reduced DM patients compared to controls. ${ }^{101}$ However, another study showed adequate immunogenicity in spite of IIM therapy and no harmful effects on the shortterm. ${ }^{102}$ In a retrospective study of $279 \mathrm{PM} / \mathrm{DM}$ cases over 15 years, thirty-seven percent were admitted for a severe pyogenic infection $(n=71)$ mostly due to aspiration pneumonia or for an opportunistic infection $(\mathrm{n}=33){ }^{103}$ There is currently no consensus criteria to identify patients who are at high-risk for Pneumocystis carinii pneumonia (PCP) infection and would therefore benefit from prophylaxis. Patients with total lymphocyte counts $<800 / \mu \mathrm{L}$ and/or CD4 lymphocyte counts $<200$ to $400 / \mu \mathrm{L}$ are likely to benefit from PCP prophylaxis prior to initiation of and in the course of immunosuppressive therapy. ${ }^{104}$ 


\section{METHOTREXATE}

MTX, an antifolate that inhibits lymphocyte proliferation, is an effective more rapidly acting second-line steroid-sparing immunosuppressant. We start oral MTX at $7.5 \mathrm{mg} /$ week, and in two weeks increase it to $15 \mathrm{mg} /$ week in two divided doses. The dose is then increased by 2.5 $\mathrm{mg}$ per week every three months to reach the maximum weekly dose of $25 \mathrm{mg}$. We also coadminister daily folic acid 0.8 to $1 \mathrm{mg}$ /day orally to prevent stomatitis.

Besides stomatitis, potential adverse events include alopecia, pneumonitis, teratogenicity, induction of malignancy, susceptibility to infections, and renal insufficiency. For bone marrow suppression and liver toxicity, we monitor complete blood count, differential count, and liver function tests every week in the first four weeks, then monthly for six months and every three months thereafter while on a stable dose. MTX-induced pneumonitis can be difficult to distinguish from myositis-associated ILD. We do not use MTX in patients with known ILD or in those with the Jo-1 antibodies.

Therapeutic effects of oral MTX are often noticeable after four to eight weeks. If we observe no improvement by that time, we escalate the dose. In non-responders and in more severe cases, we recommend MTX IV or IM treatment at a dose of $0.4-0.8 \mathrm{mg}$ per $\mathrm{kg}$ weekly infusions increasing it by $5 \mathrm{mg}$ every week to reach up to $60 \mathrm{mg}$ weekly. Leucovorin rescue on the day after parenteral MTX administration is needed for doses as high as $50 \mathrm{mg}$.

\section{AZATHIOPRINE}

AZA, an anti-metabolite that blocks T-lymphocyte proliferation, is a very effective secondline steroid-sparing immunosuppressant with delayed onset of response. AZA is administered in divided doses of 2 to $3 \mathrm{mg} / \mathrm{kg} / \mathrm{day}$, ranging from 100 to $250 \mathrm{mg}$ per day. We start with $50 \mathrm{mg}$ per day for a week before gradually increasing the dose over one to two weeks to $100-150 \mathrm{mg} / \mathrm{day}$. In three to six months we may increase it to the maximum range of 200 to $250 \mathrm{mg}$ per day. Onset of response is delayed to at least four to eight months and peaks at one to two years. It is therefore not surprising that the three-month placebo controlled trial of AZA did not show any efficacy. ${ }^{92}$ However, hand grip strength improvement after one year was no different when comparing the azathioprine to methotrexate recipients. ${ }^{95}$ Prior to AZA initiation, it has been suggested to test for thiopurine methyltransferase activity since its deficiency predicts an increased risk of leucopenia. AZA is contraindicated in homozygous cases while in heterozygous patients lower doses may be carefully tried. ${ }^{105}$ A metanalysis of 54 observational studies and 1 randomized controlled trial did not demonstrated sufficient evidence to address the effectiveness of thiopurine methyltransferase activity pretesting. In clinical practice, we monitor patients' blood cell counts weekly at the initiation of AZA then monthly. ${ }^{106}$

A flu-like reversible acute hypersensitivity reaction affects $12 \%$ of users in the first two weeks of therapy. It is associated with a rash, elevation in liver enzymes, and pancreatitis. Some may tolerate a re-challenge after recovery. Delayed adverse events include myelosuppression, hepatotoxicity, susceptibility to infection, malignancy, teratogenicity, rash, alopecia, fever, and arthralgia. 
We monitor CBC and liver enzymes every week for four weeks, then monthly for six months, and then every three months as long as the patient remains on stable AZA doses. When liver enzymes are markedly elevated (above two times the normal limit), AZA should be stopped for several months until enzymes normalize before the patient may be rechallenged, at times successfully. It is important to obtain levels of liver-specific gammaglutamyl transferase since transaminases may be released from necrotic muscle fibers.

The dose is adjusted to treatment response and to maintain the white cell count above 3,500 and the absolute lymphocyte count below 1,000. AZA administration must be interrupted if the white cell count falls below 2,500 or the absolute neutrophil count is below 1,000. Patients taking allopurinol, an inhibitor of the main detoxification pathway, require AZA dose reduction to 25 to $33 \%$ of the above. Angiotensin converting enzyme inhibitors must be avoided due to the serious risk of severe leucopenia.

\section{INTRAVENOUS IMMUNOGLOBULIN}

IVIG, a pooled gammaglobulin product from several thousand blood donors, has a complex immunomodulatory mechanism of action. It is thought to involve pathogenic autoantibodies production modulation and binding inhibition, pro-inflammatory cytokine suppression, $\mathrm{Fc}$ receptor blockade, macrophage colony stimulating factor and monocyte chemotactant protein-1 increase, alteration in T cell function, decreased in circulating CD54 lymphocytes and inhibition of cell transmigration into the muscle. A randomized-controlled trial with optional cross-over showed that IVIG $2 \mathrm{gm} / \mathrm{kg}$ administered monthy for 3 months was very effective in 9/12 treatment-resistant DM. ${ }^{94}$ Though prospective controlled trials are lacking, IVIG is also felt to be effective in PM ${ }^{107,108}$ and NM. The American Academy of Neurology 2012 guidelines recommends IVIG as possibly effective and to be considered for treating nonresponsive DM cases. ${ }^{109}$ There was insufficient evidence to support or refute the use of IVIG in PM or IBM. In a recent retrospective inception cohort, 78 JDM cases were treated steroids of whom 30 were treated additionally with IVIG. ${ }^{110}$ The IVIG group maintained similar or lower disease activity than controls. We institute IVIG in addition to IV solumedrol as initial therapy in severely affected patients to achieve a more rapid improvement. We will occasionally administer IVIG as maintenance therapy in otherwise refractory patients, or more commonly to reduce long-term CS dose. Dosing is $2 \mathrm{~g} / \mathrm{kg}$ total initially, given divided over two to five days, and then infusions are repeated every two to four weeks, with a total monthly dosage of $0.4 \mathrm{~g} / \mathrm{kg}$ to $2 \mathrm{~g} / \mathrm{kg}$.

We closely monitor patients with the first infusion, starting at a very slow rate of 25 to 50 $\mathrm{cc} / \mathrm{hr}$ for 30 minutes and increasing it progressively by $50 \mathrm{cc} / \mathrm{hr}$ every 15 to 20 minutes up to 150 to $200 \mathrm{cc} / \mathrm{hr}$. Mild reactions (headache, nausea, chills, myalgia, chest discomfort, back pain) occur in $10 \%$ and are improved with slowing the infusion rate and are preventable with pre-medication with acetaminophen, benadryl and if need be IV methylprednisolone.

Moderate rare reactions include chemical meningitis and delayed red, macular skin reaction of the palms, soles and trunk with desquamation. Acute renal failure is uncommon and related to patient dehydration and the sucrose or maltose diluent. Other severe and rare reactions are anaphylaxis, stroke, myocardial infarction or pulmonary emboli due to hyperviscocity syndrome. The latter is more likely to occur in old age, immobility, diabetes, 
thrombocytemia, hypercholesterolemia, hypergammaglobunemia, and cryoglobunemia. We avoid using IVIG in patients with several of these risk factors and place IVIG recipients on low dose aspirin prophylactically. The extremely rare patients with total IgA deficiency should not be receiving IVIG. In an uncontrolled preliminary report, seven Caucasian women (4 DM and $3 \mathrm{PM}$ ) with median disease duration of 72 months were treated with subcutaneous IG. ${ }^{111}$ Over a median follow-up period of 14 months, all patients showed a favorable clinical response leading to reduction of the daily maintenance prednisone dose by a mean of $23 \mathrm{mg}$ and three patients were able to discontinue prednisone altogether. ${ }^{111}$ These encouraging findings have not been not been validated in a controlled study.

\section{TREATMENT OF REFRACTORY PATIENTS}

In refractory patients who have not responded to second-line agents or mycophenylate mofetil, ${ }^{112}$ we start a rituximab ${ }^{113,114}$ or cyclophosphamide as third-line drugs. If patients fail to respond to those or cannot tolerate them, we consider etanercept, ${ }^{98}$ cyclosporine, tacrolimus ${ }^{115}$ and chlorambucil ${ }^{116}$ (Table 5). A large multicenter clinical trial to clarify the role of CD20 depletion using rituximab in refractory PM and DM adults and children was conducted. ${ }^{117}$ Two-hundred patients with DM, JDM or PM were randomized to receive rituximab early (Group A) or late ( 8 weeks later, Group B) in the course of this 44-week trial. This was a negative study but problems with design limit conclusions. It is likely that the study delayed treatment design hampered the detection of a significant benefit of rituximab as $83 \%$ of refractory cases met the definition of improvement following rituximab treatment. In a small uncontrolled study, rituximab improved 6 of 8 refractory SRP positive patients on manual muscle strength and/or resulted in CK decline as early as 2 months after treatment. ${ }^{118}$ Quantitative levels of serum anti-SRP antibodies also decreased after rituximab treatment. Furthermore, anti-SRP-positive myositis appears to be one of the few autoimmune diseases in which specific autoantibody levels are correlated with surrogate disease activity markers. ${ }^{119}$

In a controlled trial of etanercept, 5 of 11 subjects in the etanercept arm were successfully weaned off prednisone whereas none of the 5 placebo-recipient could be weaned off. ${ }^{98}$ The median of the average prednisone dosage after week 24 was lower in the etanercept group $(1.2 \mathrm{mg} /$ day $)$ than in the placebo group $(29.2 \mathrm{mg} /$ day $)$. Five etanercept-treated subjects and one placebo-treated case developed worsening DM rash. In an uncontrolled study of refractory JDM, etanercept did not demonstrate appreciable improvement and some patients noted worsening of disease. Therefore, caution should be taken when recommending TNF receptor inhibitors to patients with active symptoms of JDM. ${ }^{120}$

Although a case of refractory DM-ILD was successfully treated with adalimumab; ${ }^{121}$ another case of rheumatoid arthritis developed DM 4.5 years after treatment with this antiTNF-a drug. ${ }^{122}$ TNF antagonists are widely used for the treatment of rheumatoid arthritis (RA), as well as for inflammatory bowel disease, psoriasis, psoriatic arthritis, and ankylosing spondylitis. Lupus-like symptoms have been reported in $<0.2 \%$ of patients within 4-9 months of treatment for these diseases, but development of PM/DM is limited to patients with underlying RA. It is likely in the latter case that DM is a manifestation of overlap syndrome rather it being induced by adalimumab. Until an association of PM/DM 
with TNF antagonists is demonstrated in patients who do not have RA, it is premature to ascertain a causal relationship.

\section{IIM ASSOCIATED WITH ILD}

Corticosteroids are the first-line drug for IIM associated with ILD, but most patients require an adjuvant immunomodulating drugs. ${ }^{45}$ In cases of ILD refractory to steroids, mycophenolate mofetil, ${ }^{123}$ cyclosporine ${ }^{124,125}$ and tacrolimus have been shown to be effective second line agents. ${ }^{115}$ Early intervention with prednisolone and CSA combination therapy and tight control of daily CSA dose by monitoring the blood level 2 hours postdosing has improved PFT and chest imaging findings in DM cases with acute to subacute ILD. ${ }^{124}$ CSA is effective and substantially safe in patients with anti-Jo1 antisynthetase syndrome and corticosteroid-refractory ILD. ${ }^{125}$ Side effects were hypertension (5/18 patients) and creatinine increase (6/18 patients). CSA withdrawal may be associated with ILD relapse, and low-dose chronic maintenance was effective in ILD control. Rituximab and cyclophosphamide are third line options to arrest progression in cases of refractory ILD. A third of treated cases experienced resolution of pulmonary involvement, whereas $16 \%$ deteriorated. ${ }^{24}$ Factors predictive of poor ILD prognosis include older age, symptomatic ILD, lower values of vital capacity and diffusing capacity for carbon monoxide, a pattern of interstitial pneumonia on HRCT scan and lung biopsy, and steroid-refractory ILD. There is increased mortality rate in patients with deteriorating ILD as compared to those without ILD deterioration $(47.1 \%$ versus $3.3 \%)$.

\section{PROMISING THERAPIES}

Tocilizumab, a humanized anti-IL-6 receptor antibody, is FDA-approved for the treatment of moderate to severe rheumatoid arthritis. ${ }^{126}$ Ogata and Tanaka recently reported the first 2 cases of refractory PM who responded to tocilizumab with reduction in CK and in one case resolution of myalgia and stabilization of disease activity and in the other disappearance of the high-intensity zones in the thigh muscles on magnetic resonance imaging. ${ }^{126}$ Abatacept, a fusion protein between immunoglobulin and the extracellular domain of cytotoxic Tlymphocyte antigen 4, exerts its anti-inflammatory effect by down- regulating T-cell activation and is FDA-approved for moderate to severe rheumatoid arthritis. A refractory JDM case responded to abatacetpt IV and vasodilation with topical sodium thiosulfate with significant reductions in muscle and skin inflammation, decreased corticosteroid dependence, and an arrest of calcinosis progression. ${ }^{127}$ A bedridden PM patient had a very good clinical response to abatacept. ${ }^{128}$ Therefore, abatacept may hold promise as steroidsparing agent for the treatment of refractory DM.

There are anecdocatal reports of immune ablation similar to that achieved following myeloablative autologous hematopoietic stem cell transplantation through the intensive administration of alemtuzumab, an anti-CD52 antibody. A patient with refractory PM responded rapidly to a single course of treatment with alemtuzumab. ${ }^{129}$ Another case of refractory juvenile PM treated with alemtuzumab had stable clinical improvement for more than 6 years. ${ }^{130}$ However, a refractory adult PM case developed Epstein-Barr virus-driven lymphoproliferative disorder 9 weeks after alemtuzumab therapy. ${ }^{131}$ In a preliminary report, ten patients with refractory or severe DM/PM underwent allogeneic mesenchymal stem cell 
transplantation and all initially improved in their serum CK, patient global assessment by visual analogue scale and muscle strength by manual muscle test. ${ }^{132}$ However, three had recurrence of disease activity 6-8 months after the transplant of whom 2 underwent a second transplant with good clinical response in one case. The efficacy of allogeneic mesenchymal stem cell transplantation in DM or PM has yet to be confirmed in controlled trials.

\section{PHYSICAL THERAPY}

In addition to pharmacotherapy, it is generally agreed upon that physical therapy, orthotic devices, occupational therapy, and exercise are beneficial in DM, PM and NM as early as 23 weeks from the acute phase. ${ }^{133}$ A long-term follow-up study demonstrated that patients who have had JDM have persistently impaired fitness on maximal exercise using a cycle ergometer which is related to duration of active disease. ${ }^{134}$ While other studies have reported the safety and benefits of resistive exercise in active patients one to three months into their treatment, ${ }^{135}$ most of the studies have been in chronic PM or DM. ${ }^{136}$ All studies demonstrated the efficacy and safety of exercise as measured by the Functional Index, SF-36, muscle histology, muscle MRI scanning, or CPK levels. Besides improved muscle strength and increased maximal oxygen uptake, resistance exercise training of eight myositis patients resulted in marked reductions in gene expression, reflecting reductions in proinflammatory and profibrotic gene networks, together with a reduction in tissue fibrosis. ${ }^{137}$ In severe cases, we start with passive range of motion exercises initially and will usually wait for the first month to three months for strength and CK to start responding to pharmacotherapy before subjecting severely weakened muscles to a rigorous strengthening exercise program. In patients with mild to moderate weakness, we start a strengthening program after steroid initiation. Since pain from arthralgia and possibly arthritis is relieved by joint flexion, early mobilization is important to prevent flexion contractures of the large and small joints, especially in juvenile DM. There may also be a role for creatine monohydate supplementation as it improves functional performance without significant adverse effects. ${ }^{138}$

\section{PROGNOSIS}

The prognosis of DM, PM and NM is in general favorable with some exceptions. An associated malignancy portends a poor prognosis for recovery and increases mortality. SANAM is resistant to treatment. Concomitant interstitial lung disease or autoantibodies to Jo-1 or SRP predict a poorer prognosis. Overall, drug-free remissions are rare except in juvenile DM. Recent series underline that only $20 \%$ to $40 \%$ of treated PM/DM patients will achieve remission, whereas $60 \%$ to $80 \%$ will experience a polycyclic or chronic continuous course of the disease. ${ }^{139,140}$ On medium- and long-term follow-up, up to $80 \%$ of treated PM/DM patients are still disabled based on Health Assessment Questionnaire scores. ${ }^{141}$ The overall mortality ratio in PM/DM patients also remains two to threefold higher compared with the general population, with cancer, lung, cardiac complications and infections being the most common causes of deaths. ${ }^{142,143}$ Poor prognostic factors in PM/DM patients include older age, ${ }^{144}$ male gender, Non-Caucasian ethnicity, longer symptoms duration prior to diagnosis, ILD, ${ }^{145}$ cardiac involvement, dysphagia, ${ }^{146}$ cancer, ${ }^{143}$ and serum myositisspecific antibodies (including coexistence of anti-Ro52 and anti-Jo1 antibodies, SRP, 
anti-155/140, or anti-CADM-140 antibodies). PM/DM complete remission was less frequent (13.6\% versus $41.1 \%)$ and the mortality rate (47.8\% versus $7.3 \%)$ was higher in elderly patients than in younger patients. ${ }^{144}$ In a recent series the coexistence of Ro52 and Jo1 antibodies was associated with more severe myositis/joint impairment, symptomatic ILD, increased risk of cancer, and higher mortality. ${ }^{147}$ Anti-SRP antibody is associated with acute onset of refractory necrotizing myositis and antibody titers correlate with CK levels and disease activity. ${ }^{148}$ Anti-155/140 antibody is associated in adults with malignancy, whereas the presence of anti-CADM-140 antibody is associated with amyopathic DM and rapidly progressive ILD.

\section{Acknowledgments}

This publication [or project] was supported by an Institutional Clinical and Translational Science Award, NIH/ NCATS Grant Number UL1TR000001. Its contents are solely the responsibility of the authors and do not necessarily represent the official views of the NIH.

\section{References}

1. van der Meulen MFG, Bronner IM, Hoogendijk JE, et al. Polymyositis: an overdiagnosed entity. Neurol. 2003; 61:316-321.

2. Chahin N, Engel AG. Correlation of muscle biopsy, clinical course, and outcome in PM and sporadic IBM. Neurol. 2008; 5;70(6):418-424.

3. Tan JA, Roberts-Thomson PJ, Blumbergs P, et al. Incidence and prevalence of idiopathic inflammatory myopathies in South Australia: a 30-year epidemiologic study of histology-proven cases. Int J Rheum Dis. 2013 Jun; 16(3):331-8. [PubMed: 23981756]

4. Kuo CF, See LC, Yu KH, et al. Incidence, cancer risk and mortality of dermatomyositis and polymyositis in Taiwan: a nationwide population study. Br J Dermatol. 2011; 165(6):1273-9. [PubMed: 21895620]

5. Regardt M, Welin Henriksson E, Alexanderson H, et al. Patients with polymyositis or dermatomyositis have reduced grip force and health-related quality of life in comparison with reference values: an observational study. Rheumatology (Oxford). 2011; 50(3):578-85. [PubMed: 21097879]

6. Quinter SD, Chiu YE, Lyon VB, et al. Inverse Gottron's Papules: An Unusual Cutaneous Manifestation of Juvenile Dermatomyositis. Pediatr Dermatol. 2011 [Epub ahead of print]. 10.1111/j.1525-1470.2011.01585.x

7. Schmeling H, Stephens S, Goia C, et al. Nailfold capillary density is importantly associated over time with muscle and skin disease activity in juvenile dermatomyositis. Rheumatol (Oxford). 2011; 50(5):885-93.

8. Shirani Z, Kucenic MJ, Carroll CL, et al. Pruritus in adult dermatomyositis. Clin Exp Dermatol. 2004; 29:273-276. [PubMed: 15115510]

9. Hundley JL, Carroll CL, Lang W, et al. Cutaneous symptoms of dermatomyositis significantly impact patients'quality of life. J Am Acad Dermatol. 2006; 54:217-220. [PubMed: 16443050]

10. Bohan A, Peter JB. Polymyositis and dermatomyositis (first of two parts). N Engl J Med. 1975 Feb 13; 292(7):344-7. [PubMed: 1090839]

11. Bohan A, Peter JB. Polymyositis and dermatomyositis (second of two parts). N Eng J Med. 1975; 292:403-407.

12. Targoff IN, Miller FW, Medsger TA, et al. Classification criteria for the idiopathic inflammatory myopathies. Curr Opin Rheumatol. 1997; 9(6):527-535. [PubMed: 9375282]

13. Hoogendijk JE, Amato AA, Lecky, et al. 119th ENMC international workshop: trial design in adult idiopathic inflammatory myopathies, with the exception of inclusion body myositis, 10-12 October 2003, Naarden, The Netherlands. Neuromuscul Disord. 2004; 14(5):337-345. [PubMed: 15099594] 
14. Amato AA, Griggs RC. Unicorns, dragons, polymyositis and other mythical beasts. Neurol. 2003; 61:288-289.

15. Amato AA, Barohn RJ. Idiopathic inflammatory myopathies. Neurol Clin. 1997; 15:615- 648. [PubMed: 9227956]

16. Dalakas MC, Hohlfeld R. Polymyositis and dermatomyositis. Lancet. 2003; 362:971-982. [PubMed: 14511932]

17. Pal S, Sanyal D. Jaw muscle weakness: a differential indicator of neuromuscular weakness-preliminary observations. Muscle Nerve. 2011; 43(6):807-11. [PubMed: 21607965]

18. Ellis E, Ann Tan J, Lester S, et al. Necrotizing myopathy: clinicoserologic associations. Muscle Nerve. 2012; 45(2):189-94. [PubMed: 22246873]

19. Suzuki S, Ohta M, Shimizu Y, et al. Anti-signal recognition particle myopathy in the first decade of life. Pediatr Neurol. 2011; 45(2):114-6. [PubMed: 21763952]

20. Muzyka I, Barohn RJ, Dimachkie M, et al. Necrotizing Autoimmune Statin-Associated Myopathy. Journal of Clinical Neuromuscular Disease. 2011; 12(3):17.

21. Grable-Esposito P, Katzberg HD, Greenberg SA, et al. Immune-mediated necrotizing myopathy associated with statins. Muscle Nerve. 2010; 41(2):185-90. [PubMed: 19813188]

22. Niewold TB, Wu SC, Smith M, et al. Familial aggregation of autoimmune disease in juvenile dermatomyositis. Pediatrics. 2011; 127(5):e1239-46. [PubMed: 21502224]

23. Tymms KE, Webb J. Dermatopolymyositis and other connective tissue diseases: a review of 105 cases. J Rheumatol. 1985; 12(6):1140-1148. [PubMed: 4093921]

24. Marie I, Hatron PY, Dominique S, et al. Short-term and long-term outcomes of interstitial lung disease in polymyositis and dermatomyositis: a series of 107 patients. Arthritis Rheum. 2011; 63(11):3439-47. [PubMed: 21702020]

25. Hochberg MC, Feldman D, Stevens MB, et al. Antibody to Jo-1 in polymyositis/dermatomyositis: association with interstitial pulmonary disease. J Rheumatol. 1984; 11(5):663-665. [PubMed: 6334746]

26. Maoz CR, Langevitz P, Livneh A, et al. High incidence of malignancies in patients with dermatomyositis and polymyositis: an 11-year analysis. Semin Arthritis Rheum. 1998; 27(5):319324. [PubMed: 9572713]

27. Sigurgeirsson B, Lindelöf B, Edhag O, et al. Risk of cancer in patients with dermatomyositis or polymyositis. A population-based study. N Engl J Med. 1992; 326(6):363-367. [PubMed: 1729618]

28. Lakhanpal S, Bunch TW, Ilstrup DM, et al. Polymyositis-dermatomyositis and malignant lesions: does an association exist? Mayo Clin Proc. 1986; 61(8):645-653. [PubMed: 3724244]

29. Scaling ST, Kaufman RH, Patten BM. Dermatomyositis and female malignancy. Obstet Gynecol. 1979; 54(4):474-477. [PubMed: 492630]

30. Rider LG, Miller FW. Classification and treatment of the juvenile idiopathic inflammatory myopathies. Rheum Dis Clin North Am. 1997; 23(3):619-655. [PubMed: 9287380]

31. Chen YJ, Wu CY, Huang YL, et al. Cancer risks of dermatomyositis and polymyositis: a nationwide cohort study in Taiwan. Arthritis Res Ther. 2010; 12(2):R70. [PubMed: 20398365]

32. Needham M, Fabian V, Knezevic W, et al. Progressive myopathy with up-regulation of MHC-I associated with statin therapy. Neuromuscul Disord. 2007; 17(2):194-200. [PubMed: 17241784]

33. Wang Y, Barohn RJ, McVey AL, et al. Necrotizing myopathy: A unique immune-mediated myopathy. J Child Neurol. 2004; 19:207.

34. Miller T, Al-Lozi MT, Lopate G, et al. Myopathy with antibodies to the signal recognition particle: clinical and pathological features. J Neurol Neurosurg Psychiatry. 2002; 73(4):420-428. [PubMed: 12235311]

35. Zöller B, Li X, Sundquist J, et al. Risk of subsequent coronary heart disease in patients hospitalized for immune-mediated diseases: a nationwide follow-up study from Sweden. PLoS One. 2012; 7(3):e33442. [PubMed: 22438933]

36. Eimer MJ, Brickman WJ, Seshadri R, et al. Clinical status and cardiovascular risk profile of adults with a history of juvenile dermatomyositis. J Pediatr. 2011; 159(5):795-801. [PubMed: 21784434] 
37. Hill CL, Zhang Y, Sigurgeirsson B, et al. Frequency of specific cancer types in dermatomyositis and polymyositis: a population-based study. Lancet. 2001; 357(9250):96-100. [PubMed: 11197446]

38. Marie I, Guillevin L, Menard JF, et al. Hematological malignancy associated with polymyositis and dermatomyositis. Autoimmun Rev. 2011 Oct 30. [Epub ahead of print].

39. Sparsa A, Liozon E, Herrmann F, et al. Routine vs extensive malignancy search for adult dermatomyositis and polymyositis: a study of 40 patients. Arch Dermatol. 2002; 138(7):885-890. [PubMed: 12071815]

40. Titulaer MJ, Soffietti R, Dalmau J, et al. European Federation of Neurological Societies. Screening for tumours in paraneoplastic syndromes: report of an EFNS task force. Eur J Neurol. 2011; 18(1): 19-e3. [PubMed: 20880069]

41. Marie I, Josse S, Hatron PY, et al. Interstitial lung disease in anti-Jo-1 patients with antisynthetase syndrome. Arthritis Care Res (Hoboken). 2013 May; 65(5):800-8. [PubMed: 23203765]

42. Labirua A, Lundberg IE. Interstitial lung disease and idiopathic inflammatory myopathies: progress and pitfalls. Curr Opin Rheumatol. 2010; 22(6):633-8. [PubMed: 20827201]

43. Marie I, Josse S, Decaux O, et al. Comparison of long-term outcome between anti-Jo1-and antiPL7/PL12 positive patients with antisynthetase syndrome. Autoimmun Rev. 2012 Feb 3. [Epub ahead of print].

44. Marie I, Josse S, Decaux O, et al. Outcome of anti-PL12 positive patients with antisynthetase syndrome. Presse Med. 2013 Jun; 42(6 Pt 1):e153-8. [PubMed: 23428662]

45. Mimori T, Nakashima R, Hosono Y. Interstitial Lung Disease in Myositis: Clinical Subsets, Biomarkers, and Treatment. Curr Rheumatol Rep. 2012 Feb 25. [Epub ahead of print].

46. Hall JC, Casciola-Rosen L, Samedy LA, et al. Anti-melanoma differentiation-associated protein 5associated dermatomyositis: expanding the clinical spectrum. Arthritis Care Res (Hoboken). 2013 Aug; 65(8):1307-15. [PubMed: 23436757]

47. Gono T, Kawaguchi Y, Sugiura T, et al. Interferon-induced helicase (IFIH1) polymorphism with systemic lupus erythematosus and dermatomyositis/polymyositis. Mod Rheumatol. 2010; 20(5): 466-70. [PubMed: 20467774]

48. Fathi M, Barbasso Helmers S, Lundberg IE. KL-6: a serological biomarker for interstitial lung disease in patients with polymyositis and dermatomyositis. J Intern Med. 2011 [Epub ahead of print]. 10.1111/j.1365-2796.2011.02459.x

49. Gono T, Kawaguchi Y, Sugiura T, et al. Interleukin-18 is a key mediator in dermatomyositis: potential contribution to development of interstitial lung disease. Rheumatol (Oxford). 2010; 49(10):1878-81.

50. Tanizawa K, Handa T, Nakashima R, et al. The prognostic value of HRCT in myositis-associated interstitial lung disease. Respir Med. 2013 May; 107(5):745-52. [PubMed: 23485097]

51. López De Padilla CM, McNallan KT, Crowson CS, et al. BAFF expression correlates with idiopathic inflammatory myopathy disease activity measures and autoantibodies. J Rheumatol. 2013 Mar; 40(3):294-302. [PubMed: 23322463]

52. Filková M, Senolt L, Vencovský J. The role of resistin in inflammatory myopathies. Curr Rheumatol Rep. 2013 Jun.15(6):336. [PubMed: 23591826]

53. Ichimura Y, Matsushita T, Hamaguchi Y, et al. Anti-NXP2 autoantibodies in adult patients with idiopathic inflammatory myopathies: possible association with malignancy. Ann Rheum Dis. 2012 Jan 17. [Epub ahead of print].

54. Nakajima A, Yoshino K, Soejima M, et al. High Frequencies and co-existing of myositis-specific autoantibodies in patients with idiopathic inflammatory myopathies overlapped to rheumatoid arthritis. Rheumatol Int. 2011 Apr 11. [Epub ahead of print].

55. Vincze M, Molnár PA, Tumpek J, et al. An unusual association: anti-Jo1 and anti-SRP antibodies in the serum of a patient with polymyositis. Clin Rheumatol. 2010; 29(7):811-4. [PubMed: 20221841]

56. Sugie K, Tonomura Y, Ueno S. Characterization of Dermatomyositis with Coexistence of AntiJo-1 and Anti-SRP Antibodies. Intern Med. 2012; 51(7):799-802. [PubMed: 22466843] 
57. Joffe MM, Love LA, Leff RL, et al. Drug therapy of the idiopathic inflammatory myopathies: predictors of response to prednisone, azathioprine, and methotrexate and a comparison of their efficacy. Am J Med. 1993; 94(4):379-387. [PubMed: 8386437]

58. Kunimasa K, Arita M, Nakazawa T, et al. The clinical characteristics of two anti-OJ (antiisoleucyl-tRNA synthetase) autoantibody-positive interstitial lung disease patients with polymyositis/dermatomyositis. Intern Med. 2012; 51(24):3405-10. [PubMed: 23257529]

59. Kaji K, Fujimoto M, Hasegawa M, et al. Identification of a novel autoantibody reactive with 155 and $140 \mathrm{kDa}$ nuclear proteins in patients with dermatomyositis: an association with malignancy. Rheumatology (Oxford). 2007; 46:25-8. [PubMed: 16728436]

60. Rider LG, Shah M, Mamyrova G, et al. Childhood Myositis Heterogeneity Collaborative Study Group. The myositis autoantibody phenotypes of the juvenile idiopathic inflammatory myopathies. Medicine (Baltimore). 2013 Jul; 92(4):223-43. [PubMed: 23877355]

61. Ikeda N, Takahashi K, Yamaguchi Y, et al. Analysis of dermatomyositis-specific autoantibodies and clinical characteristics in Japanese patients. J Dermatol. 2011; 38(10):973-9. [PubMed: 21883412]

62. Tanizawa K, Handa T, Nakashima R, et al. HRCT features of interstitial lung disease in dermatomyositis with anti-CADM-140 antibody. Respir Med. 2011; 105(9):1380-7. [PubMed: 21632230]

63. Kobayashi I, Okura Y, Yamada M, et al. Anti-melanoma differentiation-associated gene 5 antibody is a diagnostic and predictive marker for interstitial lung diseases associated with juvenile dermatomyositis. J Pediatr. 2011; 158(4):675-7. [PubMed: 21232756]

64. Suzuki S. [Anti-SRP myopathy]. [Article in Japanese]. Rinsho Shinkeigaku. 2011; 51(11):961-3. [PubMed: 22277439]

65. Kao AH, Lacomis D, Lucas M, et al. Anti-signal recognition particle autoantibody in patients with and patients without idiopathic inflammatory myopathy. Arthritis Rheum. 2004; 50:209-215. [PubMed: 14730618]

66. Hanisch F, Müller T, Stoltenburg G, et al. Unusual manifestations in two cases of necrotizing myopathy associated with SRP-antibodies. Clin Neurol Neurosurg. 2012 Feb 3. [Epub ahead of print].

67. Christopher-Stine L, Casciola-Rosen LA, Hong G, et al. A novel autoantibody recognizing 200-kd and 100-kd proteins is associated with an immune-mediated necrotizing myopathy. Arthritis Rheum. 2010; 62(9):2757-66. [PubMed: 20496415]

68. Degardin A, Morillon D, Lacour A, et al. Morphologic imaging in muscular dystrophies and inflammatory myopathies. Skeletal Radiol. 2010; 39(12):1219-27. [PubMed: 20449587]

69. Kissel JT, Mendell JR, Rammoha KW. Microvascular deposition of complement membrane attack complex in dermatomyositis. N Engl J Med. 1986; 314:329-334. [PubMed: 3945256]

70. Emslie-Smith AM, Engel AG. Microvascular changes in early and advanced dermatomyositis: a quantitative study. Ann Neurol. 1990; 27:343-356. [PubMed: 2353792]

71. Pestronk A, Schmidt RE, Choksi R. Vascular pathology in dermatomyositis and anatomic relations to myopathology. Muscle Nerve. 2010; 42(1):53-61. [PubMed: 20544925]

72. Greenberg SA, Bradshaw EM, Pinkus JL, et al. Plasma cells in muscle in inclusion body myositis and polymyositis. Neurology. 2005; 65(11):1782-1787. [PubMed: 16344523]

73. Uchino M, Yamashita S, Uchino K, et al. Muscle biopsy findings predictive of malignancy in rare infiltrative dermatomyositis. Clin Neurol Neurosurg. 2013 May; 115(5):603-6. [PubMed: 22920633]

74. Nandakumar S, Miller CW, Kumaraguru U. T regulatory cells: an overview and intervention techniques to modulate allergy outcome. Clin Mol Allergy. 2009; 7:5. [PubMed: 19284628]

75. Antiga E, Kretz CC, Klembt R, et al. Characterization of regulatory T cells in patients with dermatomyositis. J Autoimmun. 2010; 35(4):342-50. [PubMed: 20843660]

76. Waschbisch A, Schwab N, Ruck T, et al. FOXP3+ T regulatory cells in idiopathic inflammatory myopathies. J Neuroimmunol. 2010; 225(1-2):137-42. [PubMed: 20537411]

77. Gendek-Kubiak H, Gendek EG. Fascin-expressing dendritic cells dominate in polymyositis and dermatomyositis. J Rheumatol. 2013 Feb; 40(2):186-91. [PubMed: 23118112] 
78. De Visser M, Emslie-Smith AM, Engel AG. Early ultrastructural alterations in adult dermatomyositis. Capillary abnormalities precede other structural changes in muscle. J Neurol Sci. 1989; 94(1-3):181-192. [PubMed: 2614466]

79. Zhou X, Dimachkie MM, Xiong M, et al. cDNA microarrays reveal distinct gene expression clusters in idiopathic inflammatory myopathies. Med Sci Monit. 2004; 10(7):BR191-197. [PubMed: 15232492]

80. Walsh RJ, Kong SW, Yao Y, et al. Type I interferon-inducible gene expression in blood is present and reflects disease activity in dermatomyositis and polymyositis. Arthritis Rheum. 2007; 56(11): 3784-3792. [PubMed: 17968926]

81. Bilgic H, Ytterberg SR, Amin S, et al. Interleukin-6 and type I interferon-regulated genes and chemokines mark disease activity in dermatomyositis. Arthritis Rheum. 2009; 60(11):3436-46. [PubMed: 19877033]

82. Liao AP, Salajegheh M, Nazareno R, et al. Interferon $\beta$ is associated with type 1 interferoninducible gene expression in dermatomyositis. Ann Rheum Dis. 2011; 70(5):831-6. [PubMed: 21177291]

83. Wong D, Kea B, Pesich R, et al. Interferon and biologic signatures in dermatomyositis skin: specificity and heterogeneity across diseases. PLoS One. 2012; 7(1):e29161. [PubMed: 22235269]

84. Salaroli R, Baldin E, Papa V, et al. Validity of internal expression of the major histocompatibility complex class I in the diagnosis of inflammatory myopathies. J Clin Pathol. 2012; 65(1):14-9. [PubMed: 22075187]

85. Greenberg SA, Pinkus GS, Amato AA, et al. Myeloid dendritic cells in inclusion-body myositis and polymyositis. Muscle Nerve. 2007; 35(1):17-23. [PubMed: 16969836]

86. Greenberg SA, Pinkus JL, Pinkus GS, et al. Interferon-alpha/beta-mediated innate immune mechanisms in dermatomyositis. Ann Neurol. 2005; 57(5):664-678. [PubMed: 15852401]

87. Greenberg SA, Higgs BW, Morehouse C, et al. Relationship between disease activity and type 1 interferon- and other cytokine-inducible gene expression in blood in dermatomyositis and polymyositis. Genes Immun. 2011 [Epub ahead of print]. 10.1038/gene.2011.61

88. Emslie-Smith AM, Engel AG. Necrotizing myopathy with pipestem capillaries, microvascular deposition of complement membrane attack complex (MAC), and minimal cellular infiltration. Neurol. 1991; 41:936-939.

89. Bronner IM, Hoogendijk JE, Wintzen AR, et al. Necrotizing myopathy, an unusual presentation of a steroid-responsive myopathy. J Neurol. 2003; 250:480-485. [PubMed: 12700915]

90. Mammen AL, Chung T, Christopher-Stine L, et al. Autoantibodies against 3-hydroxy-3methylglutaryl-coenzyme A reductase in patients with statin-associated autoimmune myopathy. Arthritis Rheum. 2011; 63(3):713-21.10.1002/art.30156 [PubMed: 21360500]

91. Amato AA, Barohn RJ. Inclusion body myositis: old and new concepts. J Neurol Neurosurg Psychiatry. 2009 Nov; 80(11):1186-93. [PubMed: 19864656]

92. Bunch TW, Worthington JW, Combs JJ, et al. Azathioprine with prednisone for polymyositis. Ann Intern Med. 1980; 92(3):365-369. [PubMed: 6986827]

93. Miller FW, Leitman SF, Cronin M, et al. Controlled trial of plasma exchange and leukapheresis in polymyositis and dermatomyositis. N Engl J Med. 1992; 326:1380-1384. [PubMed: 1472183]

94. Dalakas MC, Illa I, Dambrosia JM, et al. A controlled trial of high-dose intravenous immune globulin infusions as treatment for dermatomyositis. N Engl J Med. 1993; 329(27):1993-2000. [PubMed: 8247075]

95. Miller J, Walsh Y, Saminaden S, et al. Randomised double blind controlled trial of methotrexate and steroids compared with azathioprine and steroids in the treatment of idiopathic inflammatory myopathy. J Neurol Sc. 2002; 199 (Suppl 1):S53.

96. Vencovsky J, Jarosova K, Machacek S, et al. Cyclosporine A versus methotrexate in the treatment of polymyositis and dermatomyositis. Scand J Rheum. 2000; 29(2):95-102. [PubMed: 10777122]

97. Villalba L, Hicks JE, Adams EM, et al. Treatment of refractory myositis: a randomized crossover study of two new cytotoxic regimens. Arth Rheum. 1998; 41(3):392-399. [PubMed: 9506565]

98. Muscle Study Group. A randomized, pilot trial of etanercept in dermatomyositis. Ann Neurol. 2011; 70(3):427-36. [PubMed: 21688301] 
99. van de Vlekkert J, Hoogendijk JE, de Haan RJ, et al. Oral dexamethasone pulse therapy versus daily prednisolone in sub-acute onset myositis, a randomised clinical trial. Neuromuscul Disord. 2010; 20(6):382-9. [PubMed: 20423755]

100. Rodd C, Lang B, Ramsay T, et al. Incident vertebral fractures among children with rheumatic disorders 12 months after glucocorticoid initiation: a national observational study. Arthritis Care Res (Hoboken). 2012; 64(1):122-31. [PubMed: 22213727]

101. Saad CG, Borba EF, Aikawa NE, et al. Immunogenicity and safety of the 2009 non-adjuvanted influenza A/H1N1 vaccine in a large cohort of autoimmune rheumatic diseases. Ann Rheum Dis. 2011; 70(6):1068-73. [PubMed: 21540203]

102. Shinjo SK, de Moraes JC, Levy-Neto M, et al. Pandemic unadjuvanted influenza A (H1N1) vaccine in dermatomyositis and polymyositis: immunogenicity independent of therapy and no harmful effect in disease. Vaccine. 2012 Dec 17; 31(1):202-6. [PubMed: 23123020]

103. Marie I, Ménard JF, Hachulla E, et al. Infectious complications in polymyositis and dermatomyositis: a series of 279 patients. Semin Arthritis Rheum. 2011; 41(1):48-60. [PubMed: 21047670]

104. Efthimiou P, Pokharna H, Kukar M, et al. PCP chemoprophylaxis is essential for lymphopenic dermatomyositis patients treated with immunomodulators. Muscle Nerve. 2011; 43(6):918-9. [PubMed: 21488055]

105. Evans WE, Hon YY, Bomgaars L, et al. Preponderance of thiopurine S-methyltransferase deficiency and heterozygosity among patients intolerant to mercaptopurine or azathioprine. J Clin Oncol. 2001 Apr 15; 19(8):2293-301. [PubMed: 11304783]

106. Booth RA, Ansari MT, Loit E, et al. Assessment of thiopurine S-methyltransferase activity in patients prescribed thiopurines: a systematic review. Ann Intern Med. 2011 Jun 21; 154(12):81423. [PubMed: 21690596]

107. Cherin P, Piette JC, Wechsler B, et al. Intravenous gamma globulin as first line therapy in polymyositis and dermatomyositis: an open study in 11 adult patients. J Rheum. 1994; 21:10921097. [PubMed: 7932419]

108. Danieli MG, Malcangi G, Palmieri C, et al. Cyclosporin A and intravenous immunoglobulin treatment in polymyositis/dermatomyositis. Ann Rheum Dis. 2002; 61:37-41. [PubMed: 11779756]

109. Patwa HS, Chaudhry V, Katzberg H, et al. Evidence-based guideline: Intravenous immunoglobulin in the treatment of neuromuscular disorders: Report of the Therapeutics and Technology Assessment Subcommittee of the American Academy of Neurology. Neurology. 2012; 27;78(13):1009-15.

110. Lam CG, Manlhiot C, Pullenayegum EM, et al. Efficacy of intravenous Ig therapy in juvenile dermatomyositis. Ann Rheum Dis. 2011; 70(12):2089-94. [PubMed: 21978999]

111. Danieli MG, Pettinari L, Moretti R, et al. Subcutaneous immunoglobulin in polymyositis and dermatomyositis: a novel application. Autoimmun Rev. 2011; 10(3):144-9. [PubMed: 20858553]

112. Rowin J, Amato AA, Deisher N, et al. Mycophenolate mofetil in dermatomyositis: is it safe? Neurology. 2006; 66(8):1245-1247. [PubMed: 16636243]

113. Levine TD. Rituximab in the treatment of dermatomyositis: an open-label pilot study. Arthritis Rheum. 2005; 52(2):601-607. [PubMed: 15692974]

114. Noss EH, Hausner-Sypek DL, Weinblatt ME. Rituximab as therapy for refractory polymyositis and dermatomyositis. J Rheumatol. 2006; 33(5):1021-1026. [PubMed: 16541475]

115. Oddis CV, Sciurba FC, Elmagd KA, et al. Tacrolimus in refractory polymyositis with interstitial lung disease. Lancet. 1999; 22;353(9166):1762-1763.

116. Cagnoli M, Marchesoni A, Tosi S. Combined steroid, methotrexate and chlorambucil therapy for steroid-resistant dermatomyositis. Clin Exp Rheumatol. 1991; 9(6):658-659. [PubMed: 1764849]

117. Oddis CV, Reed AM, Aggarwal R, et al. Rituximab in the Treatment of Refractory Adult and Juvenile Dermatomyositis and Adult Polymyositis: A Randomized, Placebo-phase Trial. Arthritis and Rheumatism. Arthritis Rheum. 2013 Feb; 65(2):314-24. [PubMed: 23124935]

118. Valiyil R, Casciola-Rosen L, Hong G, et al. Rituximab therapy for myopathy associated with antisignal recognition particle antibodies: a case series. Arthritis Care Res (Hoboken). 2010; 62(9): 1328-34. [PubMed: 20506493] 
119. Benveniste O, Drouot L, Jouen F, et al. Correlation of anti-signal recognition particle autoantibody levels with creatine kinase activity in patients with necrotizing myopathy. Arthritis Rheum. 2011; 63(7):1961-71. [PubMed: 21400483]

120. Rouster-Stevens KA, Ferguson L, Morgan G, et al. Pilot study of etanercept in patients with refractory juvenile dermatomyositis. Arthritis Care Res (Hoboken). 2013 Oct 14. [Epub ahead of print]. 10.1002/acr.22198

121. Park JK, Yoo HG, Ahn DS, et al. Successful treatment for conventional treatment-resistant dermatomyositis-associated interstitial lung disease with adalimumab. Rheumatol Int. 2011 Nov 17. [Epub ahead of print].

122. Brunasso AM, Scocco GL, Massone C. Dermatomyositis during adalimumab therapy for rheumatoid arthritis. J Rheumatol. 2010; 37(7):1549-50. [PubMed: 20595297]

123. Morganroth PA, Kreider ME, Werth VP. Mycophenolate mofetil for interstitial lung disease in dermatomyositis. Arthritis Care Res (Hoboken). 2010; 62(10):1496-501. [PubMed: 20506189]

124. Kotani T, Takeuchi T, Makino S, et al. Combination with corticosteroids and cyclosporin-A improves pulmonary function test results and chest HRCT findings in dermatomyositis patients with acute/subacute interstitial pneumonia. Clin Rheumatol. 2011; 30(8):1021-8. [PubMed: 21340495]

125. Cavagna L, Caporali R, Abdì-Alì L, et al. Cyclosporine in anti-Jo1-positive patients with corticosteroid-refractory interstitial lung disease. J Rheumatol. 2013 Apr; 40(4):484-92. [PubMed: 23418387]

126. Ogata A, Tanaka T. Tocilizumab for the treatment of rheumatoid arthritis and other systemic autoimmune diseases: current perspectives and future directions. Int J Rheumatol. 2012; 2012:946048. Epub 2012 Jan 18. [PubMed: 22315615]

127. Arabshahi B, Silverman RA, Jones OY, et al. Abatacept and sodium thiosulfate for treatment of recalcitrant juvenile dermatomyositis complicated by ulceration and calcinosis. J Pediatr. 2012; 160(3):520-2. [PubMed: 22244459]

128. Musuruana JL, Cavallasca JA. Abatacept for treatment of refractory polymyositis. Joint Bone Spine. 2011; 78(4):431-2. [PubMed: 21550833]

129. Thompson B, Corris P, Miller JA, et al. Alemtuzumab (Campath-1H) for treatment of refractory polymyositis. J Rheumatol. 2008 Oct; 35(10):2080-2. [PubMed: 18843768]

130. Reiff A, Shaham B, Weinberg KI, et al. Anti-CD52 antibody-mediated immune ablation with autologous immune recovery for the treatment of refractory juvenile polymyositis. J Clin Immunol. 2011; 31(4):615-22. [PubMed: 21541793]

131. Cooles FA, Jackson GH, Menon G, et al. Epstein-Barr virus-driven lymphoproliferative disorder post-CAMPATH-1H (alemtuzumab) in refractory polymyositis. Rheumatology (Oxford). 2011; 50(4):810-2. [PubMed: 21208978]

132. Wang D, Zhang H, Cao M, et al. Efficacy of allogeneic mesenchymal stem cell transplantation in patients with drug-resistant polymyositis and dermatomyositis. Ann Rheum Dis. 2011; 70(7): 1285-8. [PubMed: 21622775]

133. Varjú C, Pethö E, Kutas R, et al. The effect of physical exercise following acute disease exacerbation in patients with dermato/polymyositis. Clin Rehabil. 2003; 17(1):83-7. [PubMed: 12617382]

134. Mathiesen PR, Ørngreen MC, Vissing J, et al. Aerobic fitness after JDM--a long-term follow-up study. Rheumatology (Oxford). 2013 Feb; 52(2):287-95. [PubMed: 23001614]

135. Alexanderson H, Stenström CH, Jenner G, et al. The safety of a resistive home exercise program in patients with recent onset active polymyositis or dermatomyositis. Scand J Rheumatol. 2000; 29(5):295-301. [PubMed: 11093595]

136. Alexanderson H. Exercise effects in patients with adult idiopathic inflammatory myopathies. Curr Opin Rheumatol. 2009; 21(2):158-163. [PubMed: 19339927]

137. Nader GA, Dastmalchi M, Alexanderson H, et al. A longitudinal, integrated, clinical, histological and mRNA profiling study of resistance exercise in myositis. Mol Med. 2010; 16(11-12):45564. [PubMed: 20809047]

138. Chung YL, Alexanderson H, Pipitone N, et al. Creatine supplements in patients with idiopathic inflammatory myopathies who are clinically weak after conventional pharmacologic treatment: 
Six-month, double-blind, randomized, placebo-controlled trial. Arthritis Rheum. 2007; 57(4): 694-702. [PubMed: 17471547]

139. Marie I, Hachulla E, Hatron PY, et al. Polymyositis and dermatomyositis: short term and longterm outcome, and predictive factors. J Rheumatol. 2001; 28:2230-7. [PubMed: 11669162]

140. Bronner IM, van der Meulen MF, de Visser M, et al. Long-term outcome in polymyositis and dermatomyositis. Ann Rheum Dis. 2006; 65:1456-61. [PubMed: 16606652]

141. Ponyi A, Borgulya G, Constantin T, et al. Functional outcome and quality of life in adult patients with idiopathic inflammatory myositis. Rheumatology (Oxford). 2005; 44:83-8. [PubMed: 15381789]

142. Limaye V, Hakendorf $P$, Woodman RJ, et al. Mortality and its predominant causes in a large cohort of patients with biopsy-determined inflammatory myositis. Intern Med J. 2012; 42(2): 191-8. [PubMed: 21118413]

143. Airio A, Kautiainen H, Hakala M. Prognosis and mortality of polymyositis and dermatomyositis patients. Clin Rheumatol. 2006; 25:234-9. [PubMed: 16477398]

144. Marie I, Hatron PY, Levesque H, et al. Influence of age on characteristics of polymyositis and dermatomyositis in adults. Medicine (Baltimore). 1999; 78:139-47. [PubMed: 10352646]

145. Yamasaki Y, Yamada H, Ohkubo M, et al. Longterm survival and associated risk factors in patients with adult-onset idiopathic inflammatory myopathies and amyopathic dermatomyositis: experience in a single institute in Japan. J Rheumatol. 2011; 38:1636-43. [PubMed: 21572147]

146. Danko K, Ponyi A, Constantin T, et al. Long-term survival of patients with idiopathic inflammatory myopathies according to clinical features: a longitudinal study of 162 cases. Medicine (Baltimore). 2004; 83:35-42. [PubMed: 14747766]

147. Marie I, Hatron PY, Dominique S, et al. Short-Term and Long-Term Outcome of Anti-Jo1Positive Patients with Anti-Ro52 Antibody. Semin Arthritis Rheum. 2011 Nov 9. [Epub ahead of print].

148. Benveniste O, Drouot L, Jouen F, et al. Correlation of anti-signal recognition particle autoantibody levels with creatine kinase activity in patients with necrotizing myopathy. Arthritis Rheum. 2011; 63:1961-71. [PubMed: 21400483] 
- The idiopathic inflammatory myopathies (IIM) consist of rare heterogenous autoimmune disorders that present with marked proximal and symmetric muscle weakness, except for distal and asymmetric weakness in inclusion body myositis (IBM).

- Besides frequent creatine kinase (CK) elevation, the electromyogram confirms the presence of an irritative myopathy.

- Extramuscular involvement affects a significant number of cases with interstitial lung disease (ILD), cutaneous in dermatomyositis (DM), systemic or joint manifestations and increased risk of malignancy especially in DM.

- Myositis specific autoantibodies influence phenotype of the IIM. Jo-1 antibodies are frequently associated with ILD and the newly described HMG-CoA reductase antibodies are characteristic of autoimmune necrotizing myopathy (NM).

- Muscle pathology ranges from inflammatory exudates of variable distribution, to intact muscle fiber invasion, necrosis, phagocytosis and in the case of IBM rimmed vacuoles and protein deposits.

- Despite many similarities, the IIM are a quite heterogeneous from the histopathological and pathogenetic standpoints in addition to some clinical and treatment-response difference. 


\section{Figure 1a}

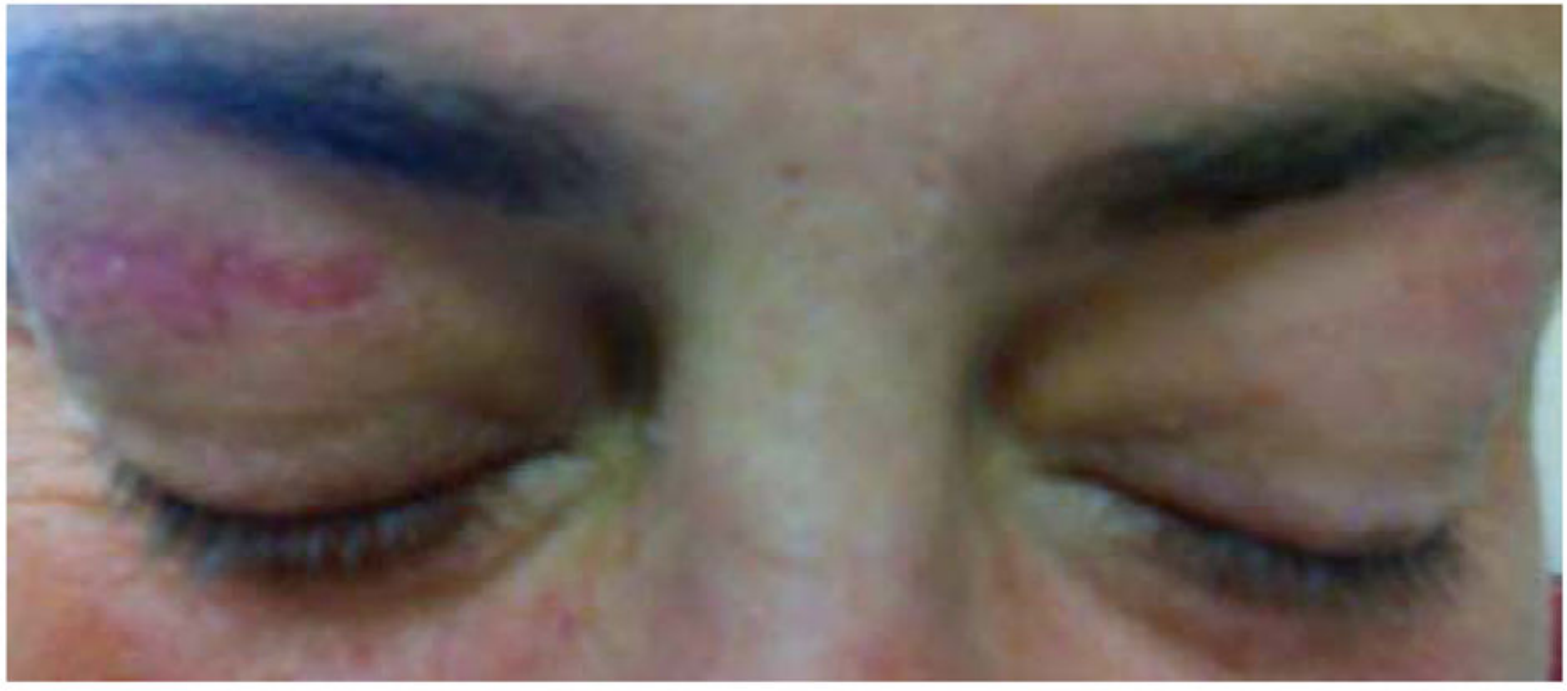




\section{Figure 1b}

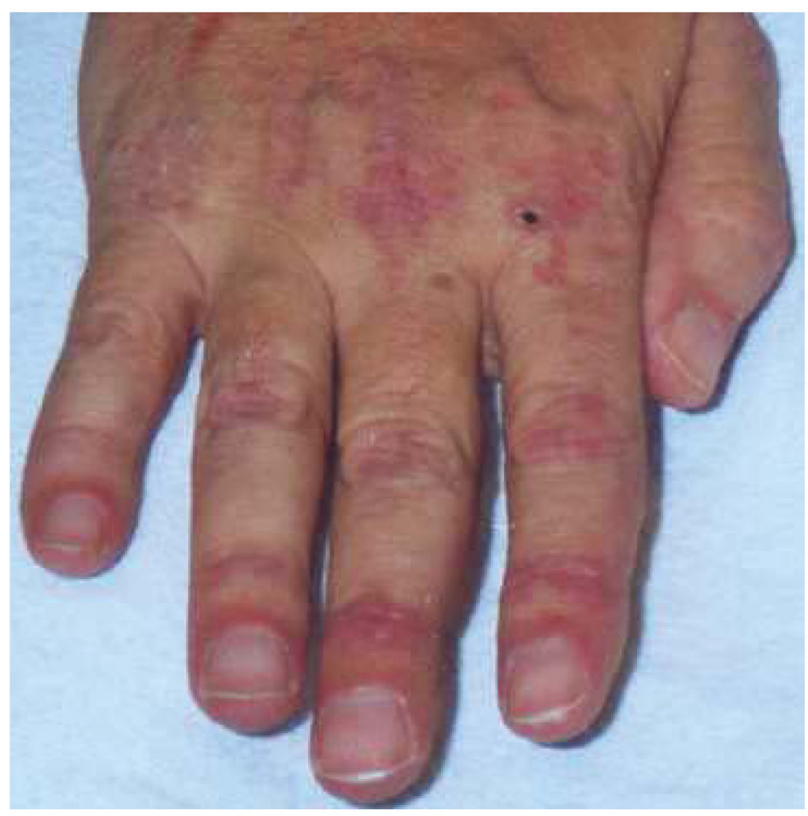

Figure 1c

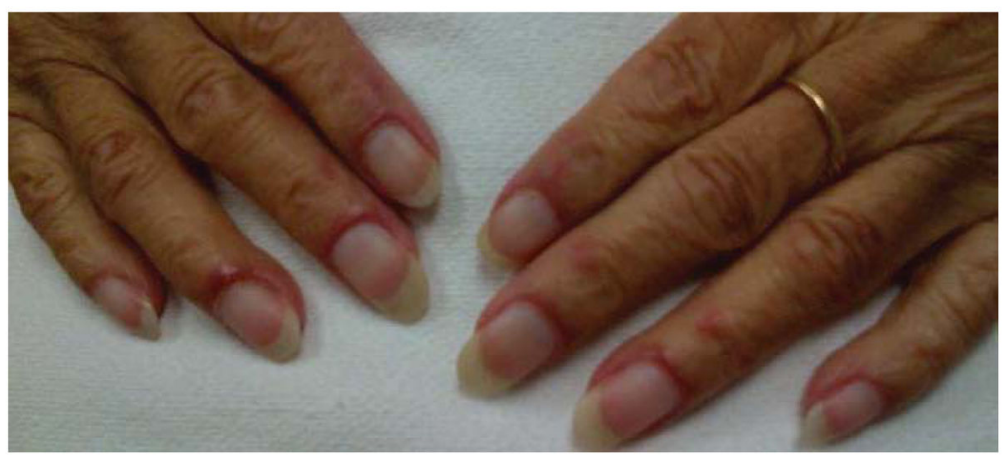

Figure 1.

Figure 1a. Heliotrope rash and periorbital edema and erythema in DM

Figure 1b. Violaceous erythematous scaly papular rash in DM - Gottron's papules, with cutaneous ulceration and perinungal hyperemia.

Figure 1c. Periungal hyperemia in DM 


\section{Figure 2a}

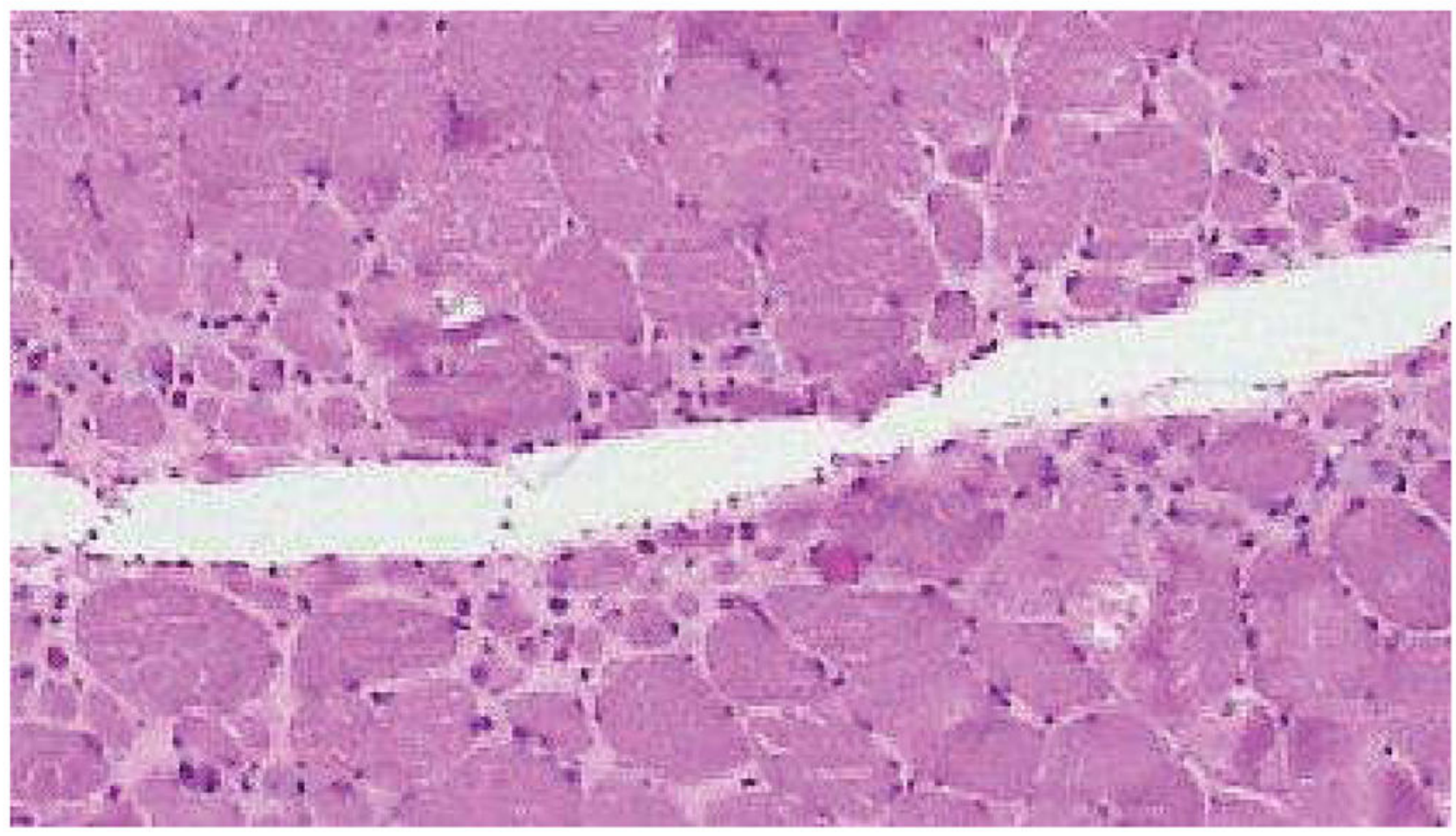




\section{Figure 2b}

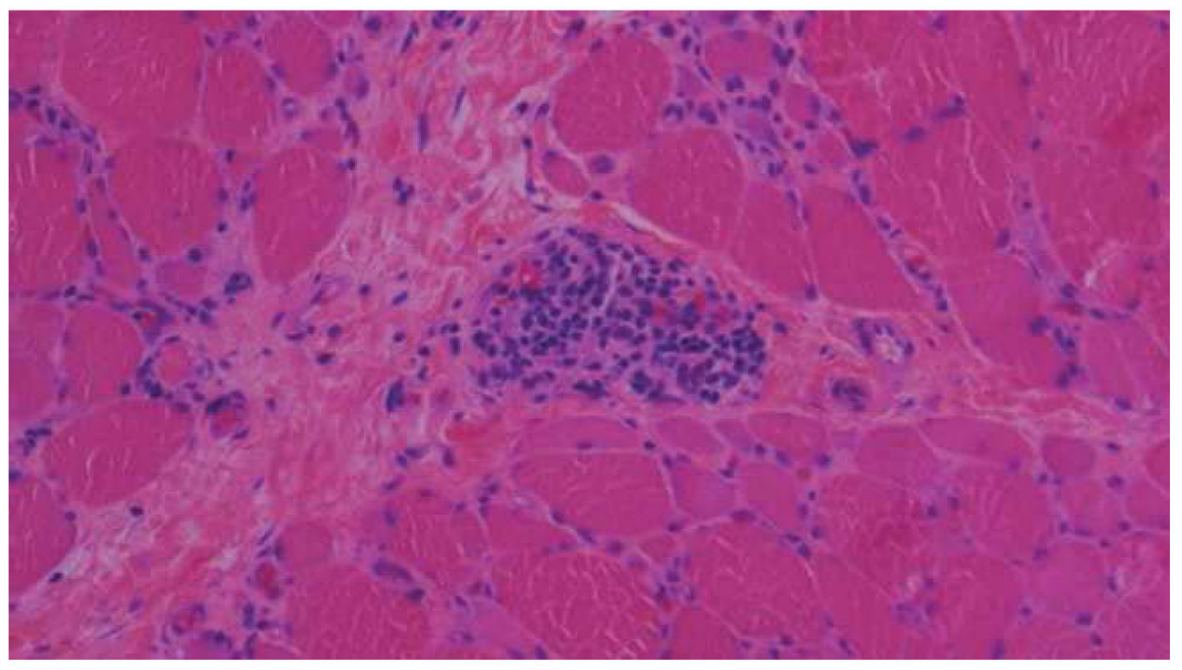


Figure 2c

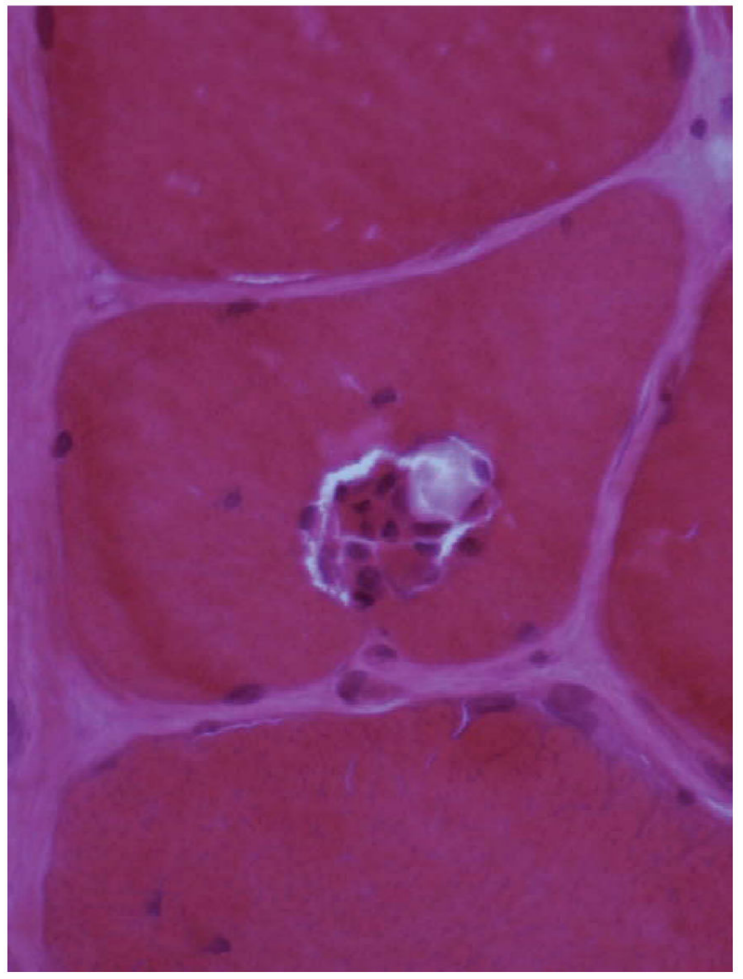


Figure 2d

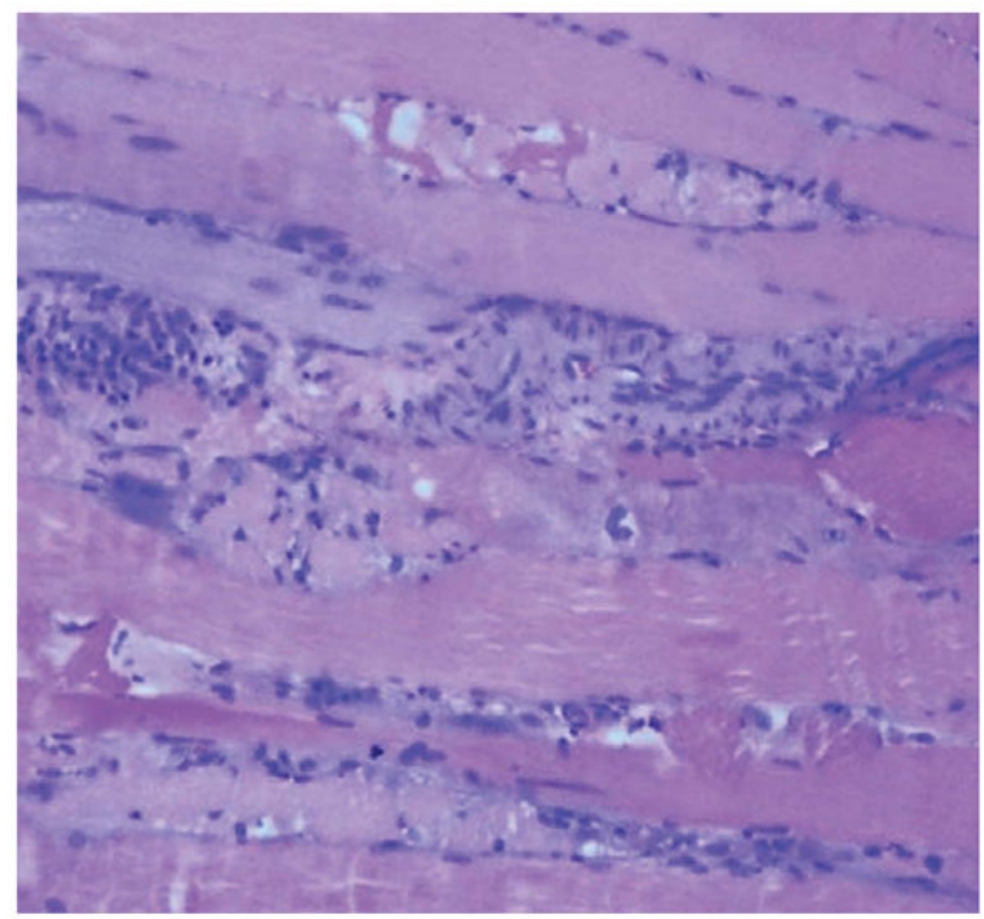

Figure 2.

Figure 2a. DM: Perifascular atrophy - Hematoxylin and eosin

Figure 2b. DM: Perimysial inflammation - Hematoxylin and eosin

Figure 2c. PM: Central invasion of non-necrotic fibers by inflammatory infiltrates Hematoxylin and eosin

Figure 2d. NM: Multiple necrotic fibers undergoing phagocytosis - Hematoxylin and eosin longitudinal section 


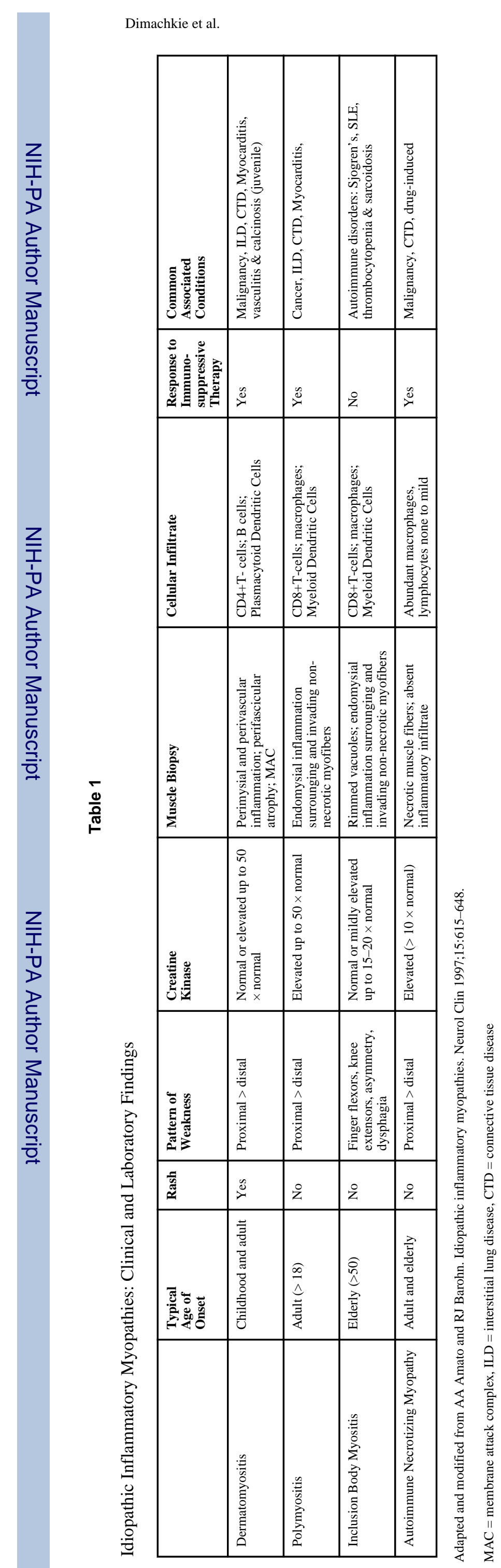

Page 35 


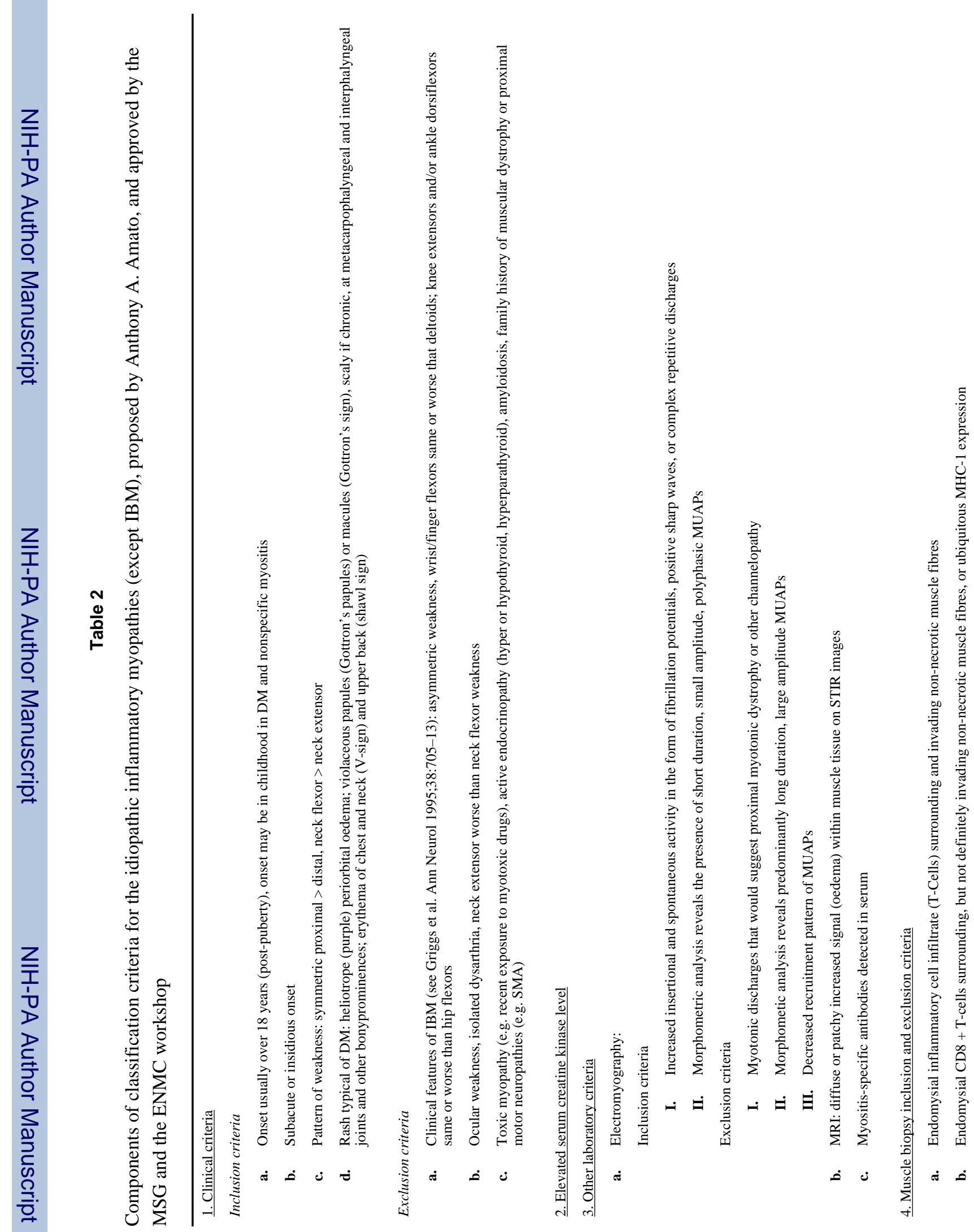

Neurol Clin. Author manuscript; available in PMC 2015 August 01. 


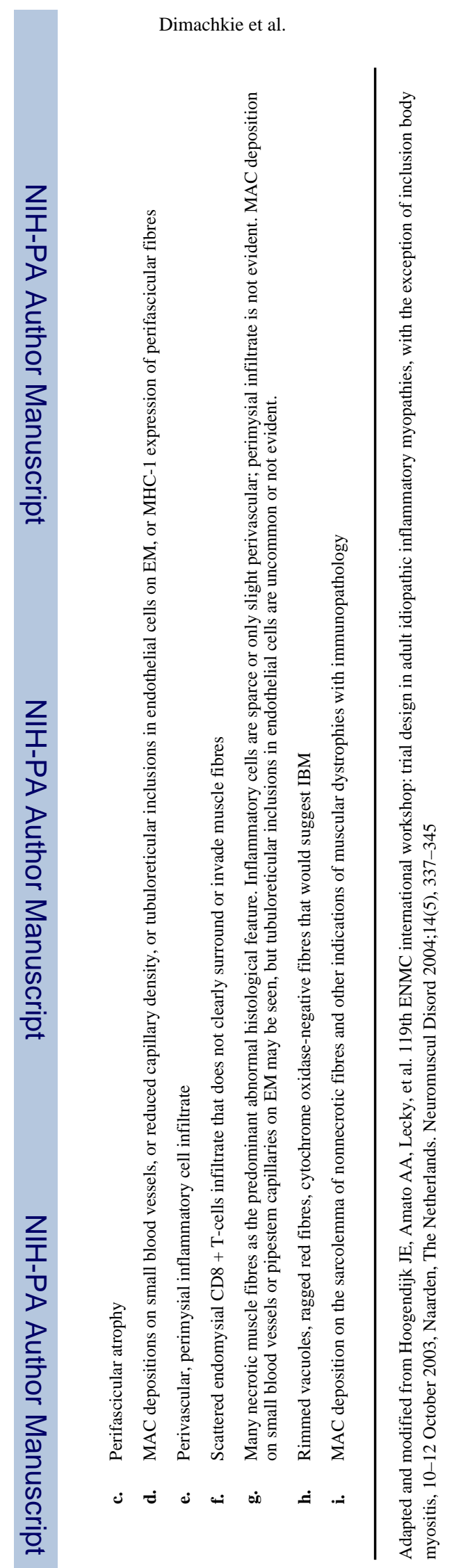

Neurol Clin. Author manuscript; available in PMC 2015 August 01. 


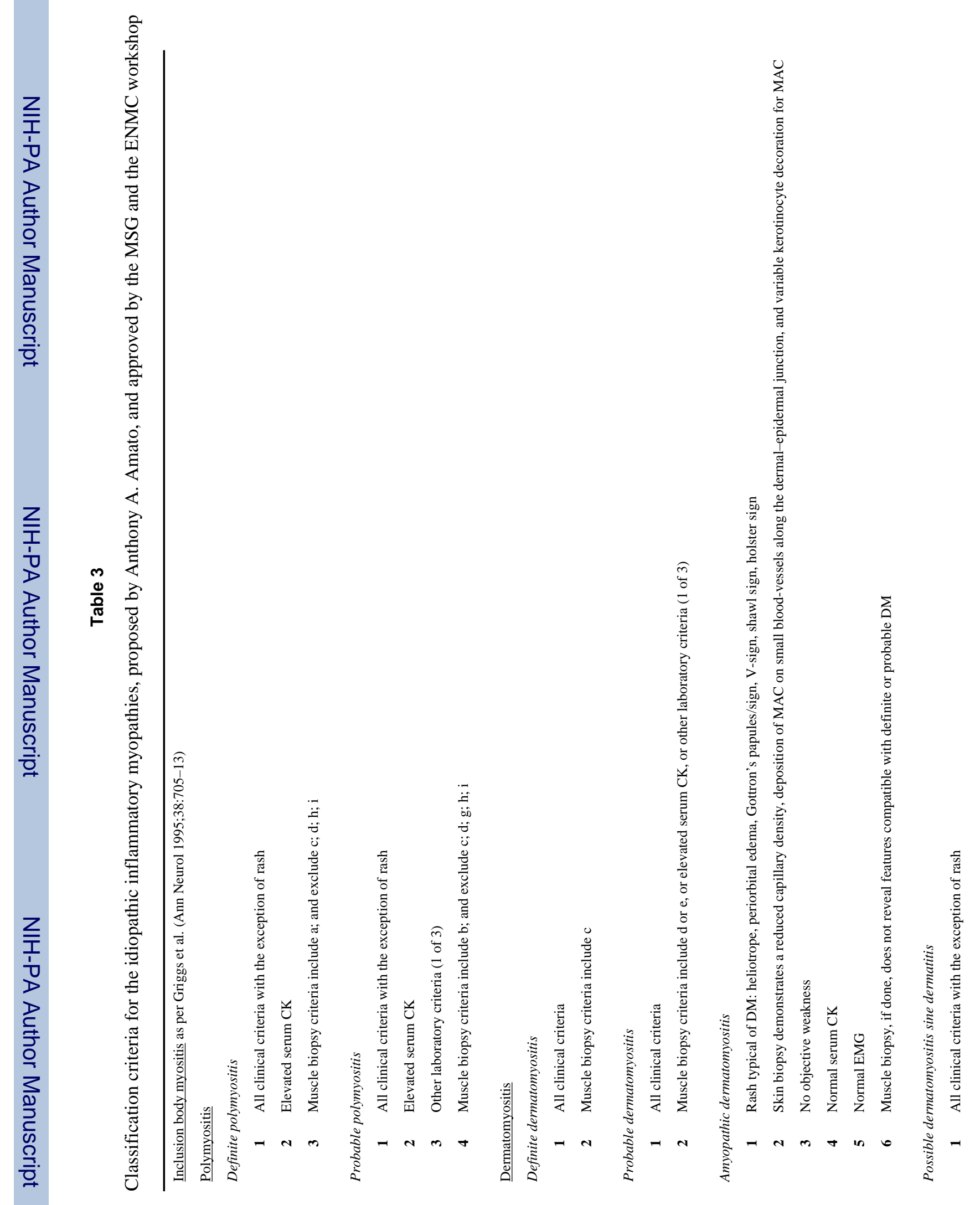

Neurol Clin. Author manuscript; available in PMC 2015 August 01. 


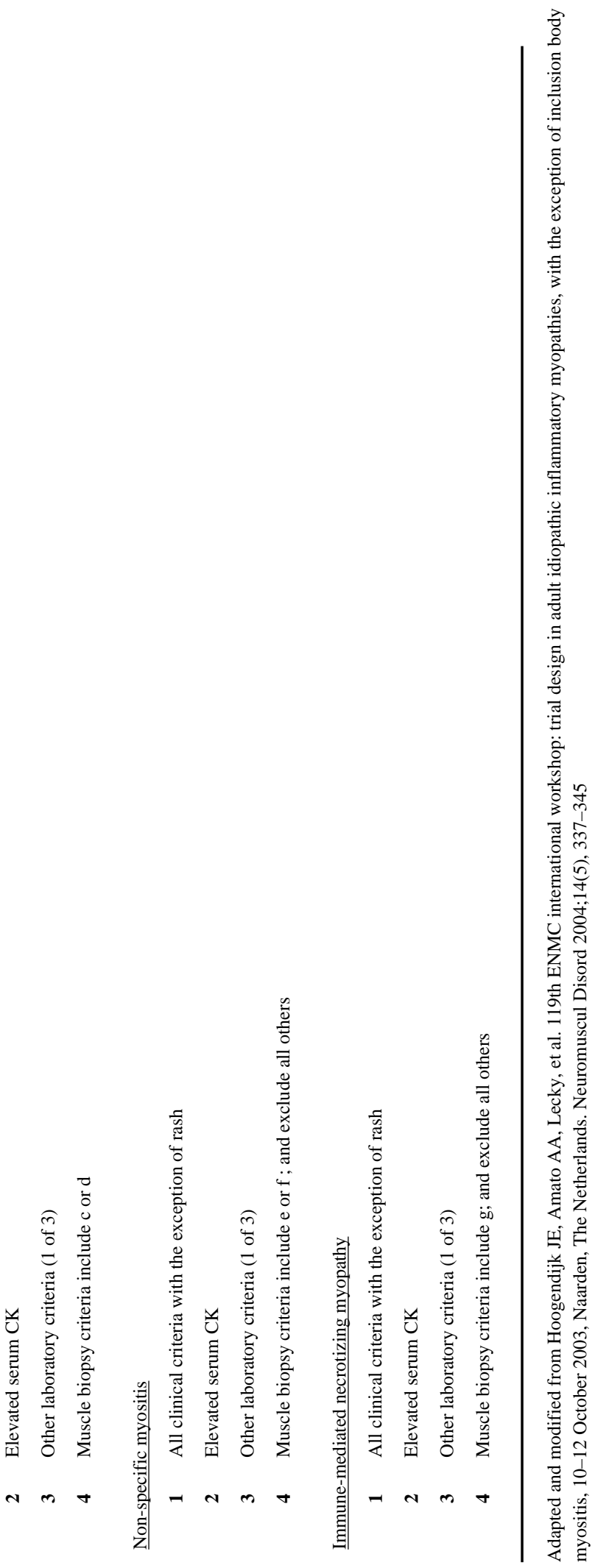

Neurol Clin. Author manuscript; available in PMC 2015 August 01. 


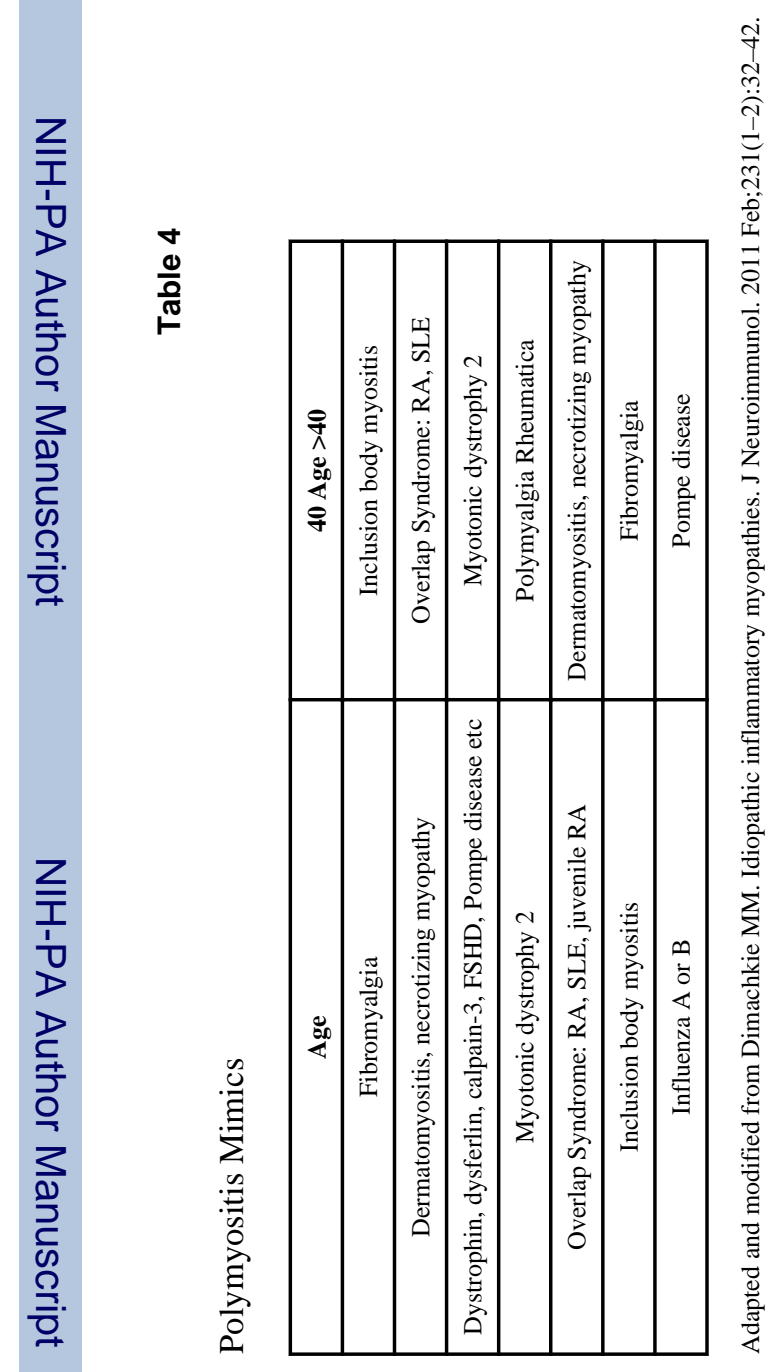

Neurol Clin. Author manuscript; available in PMC 2015 August 01. 


\begin{tabular}{|c|c|c|c|c|c|c|c|c|c|c|c|c|c|}
\hline 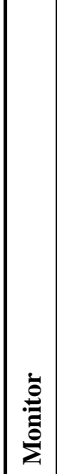 & 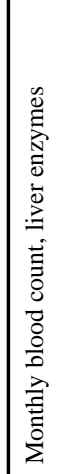 & 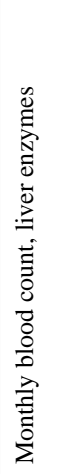 & 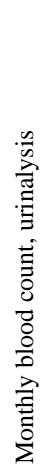 & 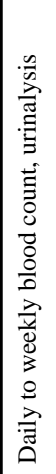 & 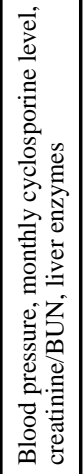 & 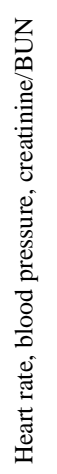 & 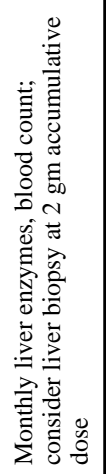 & 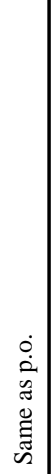 & 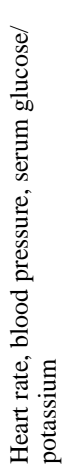 & 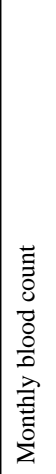 & 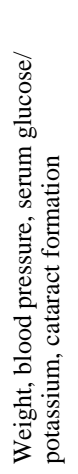 & 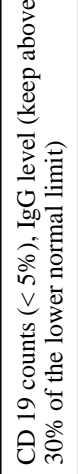 & 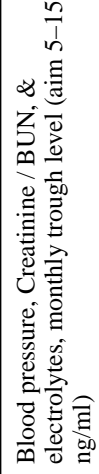 \\
\hline
\end{tabular}

